\title{
A MediaÇÃo \\ EM UM CAMPO DE ANÁLISE INTERDISCIPLINAR: \\ O APORTE DA TEORIA DO MULTIJURIDISMO \\ DE ÉTIENNE LE ROY
}

ORLANDO VILLAS BOAS FILHO ${ }^{\dagger}$

RESUMO: Este artigo pretende analisar o aporte da teoria do multijuridismo de Étienne Le Roy para a compreensão da mediação. Assim, considerando que esse autor associa a mediação ao que ele designa de "juridicidade", será realizada, em primeiro lugar, uma breve alusão à distinção entre "direito" e "juridicidade" por ele proposta. Em seguida, será focalizado o delineamento conceitual dado à mediação por Étienne Le Roy, com especial ênfase na progressiva aquisição de centralidade que esta recebe em seu pensamento. A partir daí, tendo por horizonte a noção de juridicidade, será enfocada a tese do autor acerca da mediação como um "conceito-pivô e dialogal da regulação global das sociedades". Finalmente, em termos conclusivos, procurar-se-á sublinhar o quanto uma consideração mais apurada dos aportes antropológicos pode contribuir para a compreensão da complexidade assumida pela regulação jurídica contemporânea e, em particular, da mediação.

PAlaVRAS-ChaVe: Mediação; Regulação jurídica; Juridicidade; Antropologia Jurídica; Multijuridismo.

\footnotetext{
† Professor da Faculdade de Direito da Universidade de São Paulo e Professor Associado da Faculdade de Direito da Universidade Presbiteriana Mackenzie. Graduação e Licenciatura Plena em História pela Universidade de São Paulo. Graduação em Direito pela Pontifícia Universidade Católica de São Paulo. Graduação em Filosofia pela Universidade de São Paulo. Mestrado em Direito e Doutorado em Direito, na área de concentração Filosofia e Teoria Geral do Direito, pela Universidade de São Paulo. Pós-Doutorado na Université de Paris X - Nanterre, França. PósDoutorado na École Normale Supérieure de Paris, França.
} 
ABSTRACT: This article intends to analyze the contribution of Étienne Le Roy's theory of multijuridism to the understanding of mediation. Thus, considering that this author associates mediation with what he calls "juridicity", a brief allusion will be made to the distinction, proposed by him, between "law" and "juridicity". Next, we will focus the conceptual design given to the mediation by Étienne Le Roy, with special emphasis on the progressive acquisition of centrality that it receives in his theory. After that, having as a horizon the notion of juridicity, the article focusses the author's thesis on mediation as a "pivotal and dialogal concept of the global regulation of societies". Finally, in conclusive terms, it will be emphasized how a more accurate consideration of the anthropological approach can contribute to the understanding of the complexity assumed by the contemporary legal regulation and, in particular, of the mediation.

KEYWORDS: Mediation; Legal Regulation; Juridicity; Legal Anthropology; Multijuridism. 


\section{SUMÁRIO:}

I. INTRODUÇ̃̃ O..................................................................................1115

II. DiREITO E JURIDICIDADE NA TEORIA DO MULTIJURIDISMO .........1119

III. O Que É Mediação? Um Delineamento ConCeitual

a Partir de Étienne Le Roy

1. A desconstrução da representação espontânea que atrela direito e mediação

2. A progressiva aquisição de centralidade da mediação no pensamento de Étienne Le Roy: de forma de obtenção de compromissos negociados a conceito-pivô e dialogal da regulação global das sociedades ......................................1136

3. Mediação e juridicidade .............................................1144

IV. CONCLUSÃO ..............................................................................1149

V. REFERÊNCIAS ...................................................................1152

\section{TABLE OF CONTENTS:}

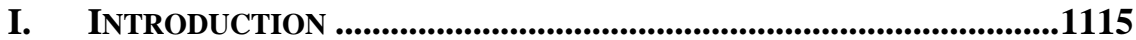

II. LAW AND JURIDICITY IN THE MULTIJURIDISM THEORY..............1119

III. What Is MEDIATION? A CONCEPTUAL OUTLINE BASED ON ÉTIENNE LE ROY

1. The deconstruction of the spontaneous representation that associates law and mediation ......................................1129

2. The progressive acquisition of centrality of mediation in Étienne Le Roy's theory: from a way of obtaining negotiated commitments to a pivotal and dialogical concept of societies global regulation ..........................................................1136

3. Mediation and Juridicity ................................................1144

IV. CONCLUSION ...................................................................1149

V. REFERENCES .................................................................1152 


\section{INTRODUÇÃO}

A mediação é objeto de um amplo debate e de uma abundante e diversificada literatura. Trata-se de uma questão de claro interesse interdisciplinar que, por esse motivo, permite um entrecruzamento rico e variado de análises que, entretanto, nem sempre acontece. É comum que os juristas, ciosos de suas taxinomias e classificações dogmáticas, tendam a ser refratários a esse intercurso frutífero que a interdisciplinaridade pode ensejar. Por outro lado, os cientistas sociais, não poucas vezes, ao serem corrosivamente críticos e desqualificarem as formulações conceituais dos juristas, não apenas obstaculizam a construção de um campo comum para a discussão de temas complexos, como, inclusive, em alguns casos, acabam por comprometer o alcance de suas próprias análises na medida em que dela excluem um horizonte prático e conceitual que, com todos os problemas que possa ter, é essencial à compreensão das dinâmicas envolvidas na mediação. É bem verdade que a interdisciplinaridade não deve ser confundida com a abertura indiscriminada de campos disciplinares diversos e com a hibridação temerária de métodos. ${ }^{1}$ Por outro lado, conforme ressaltava André-Jean Arnaud, um grande obstáculo à interdisciplinaridade consiste na dificuldade dos pesquisadores de disciplinas distintas de se entenderem acerca do que estão discutindo, uma vez que tendem a constituir o objeto de análise segundo o cânon de suas respectivas áreas de proveniência. ${ }^{2}$

Apesar de identificar, no início dos anos 1990, uma situação de cacofonia no âmbito dos estudos sociojurídicos, André-Jean Arnaud já sublinhava os expressivos esforços realizados pelas diversas disciplinas concernidas na empreitada interdisciplinar, destacando, especialmente, $\mathrm{o}$

${ }^{1}$ A respeito, Étienne Le Roy, referindo-se à Jacques Caillosse, alude às cautelas necessárias para que sejam evitadas as "hybridations méthodologiques hasardeuses". LE ROY, Étienne. Place de la juridicité dans la médiation. Jurisprudence: Revue critique, No. 4 (La médiation. Entre renouvellement de l'offre de justice et droit), 2013, p. 194.

2 Diagnosticando a situação de cacofonia no âmbito dos estudos sociojurídicos, AndréJean Arnaud ressaltava que "la pierre sur laquelle achoppa et achoppe encore l'interdisciplinarité consiste dans l'impossibilité qu'on les tenants des diverses disciplines, de s'entendre sur l'objet - Droit. Chacun le constitue selon les canons propres à sa formation disciplinaire. Pour l'instant, c'est encore la cacofonie". ARNAUD, André-Jean. Droit et Société: du constat à la construction d'un champ commun. Droit et Société, No. 20-21, 1992, p. 25.

3 JOURNAL OF INSTITUTIONAL STUDIES 2 (2017) 
papel da antropologia. ${ }^{3}$ Entretanto, embora tenha sido grande entusiasta e incansável promotor da pesquisa interdisciplinar, Arnaud era refratário às soluções artificialmente unificadoras e aos sincretismos teóricos. ${ }^{4}$ Insistia, assim, no fato de que o desenvolvimento desse tipo de pesquisa demandaria, entre outras coisas, novos fundamentos epistemológicos, cujos traços, aliás, procurava mapear. ${ }^{5}$ Mais recentemente, Jacques Caillosse alerta para os riscos de se misturar indiscriminadamente os gêneros de análise e celebrar acriticamente, por suas supostas virtudes intrínsecas, a hibridação metodológica. Segundo esse autor, não obstante as fronteiras disciplinares parecerem, comumente, esclerosadas e contraproducentes, o fato é que a vontade ingênua de as abolir seria insensata na medida em que poderia produzir um território intelectual totalmente desestruturado e desprovido de consistência. ${ }^{6}$

Contudo, apesar de todas as dificuldades ínsitas à realização da pesquisa jurídica interdisciplinar, não é possível desconsiderar os expressivos esforços que se desenvolvem nesse sentido e os instigantes resultados que deles derivam. Logo, desde que tomadas as precauções necessárias para se evitar um ecumenismo ingênuo, a promoção de uma pesquisa de complementaridades, nos termos em que Jacques Commaille a define, se afigura como muito frutífera. ${ }^{7}$ Aliás, alguns temas, em virtude

${ }^{3}$ Cf. ARNAUD, André-Jean. Droit et Société: du constat à la construction d'un champ commun. Droit et Société, No. 20-21, 1992, p. 25.

${ }^{4}$ Cf. ARNAUD, André-Jean. Le droit trahi par la sociologie: Une pratique de

l'histoire. Paris: Librairie Générale de Droit et de Jurisprudence, 1998, p. 95.

${ }^{5}$ Cf. ARNAUD, André-Jean. Droit et Société: du constat à la construction d'un champ commun. Droit et Société, No. 20-21, 1992, p. 27-34.

${ }^{6}$ Segundo esse autor, "il n'a nullement été question de mélanger les genres ou de célébrer, pour elles-mêmes, les vertus de l'hybridation méthodologique! Autant les cloisonnements disciplinaires apparaissent souvent sclérosants et contre-productifs, autant la volonté naïve de les abolir serait proprement insensée: elle laisserait voir un territoire intellectuel déstructuré et dépourvu de toute consistance. L'essentiel ne doit surtout pas être oublié: il appartient à chaque discipline scientifique de déterminer son objet, du seul point de vue des questions qu'elle se pose et des méthodes qu'elle privilégie pour les mettre à jour". CAILLOSSE, Jacques. La sociologie politique du droit, le droit et les juristes. Droit et Société, No. 77, 2011, p. 204.

${ }^{7} \mathrm{Cf}$. COMMAILLE, Jacques. À quoi nous sert le droit pour comprendre sociologiquement les incertitudes des sociétés contemporaines? Sociologies (Dossiers, Sociétés en mouvement), 07 mar. 2016, 2016, p. 9. Disponível em: $<$ http://sociologies.revues.org/5278>. Acesso em: 5 de fevereiro de 2018. 
de sua complexidade, fazem com que uma abordagem desse tipo, em que a interação entre diversos campos disciplinares permite o enriquecimento da análise, se torne indispensável. ${ }^{8}$ Tal é o caso da mediação, cujo exame adequado não pode mais ser efetuado a partir de perspectivas estanques e autoencapsuladas. ${ }^{9}$ Assim, com o intuito de contribuir para o desenvolvimento de uma discussão que esteja à altura da complexidade da mediação, este artigo pretende, à guisa de ilustração, indicar o potencial heurístico que a antropologia jurídica pode oferecer para a abordagem dessa questão. Para tanto, enfocará a proposta de Étienne Le Roy, pois considera que ela, ao mobilizar a noção de juridicidade, auxilia significativamente no desvelamento de aspectos não devidamente apreendidos pelas abordagens convencionais.

Por conseguinte, cumpre notar que o artigo, naturalmente, não se propõe a reconstruir o amplo e multifacetado debate existente sobre a mediação nem analisar a vasta literatura que versa sobre ela, posto que uma empreitada dessa magnitude não seria sequer compatível com suas dimensões. Seu propósito é bem mais modesto. Consiste apenas em aquilatar, por intermédio de uma abordagem despretensiosa da teoria do multijuridismo de Étienne Le Roy, o quanto a antropologia jurídica pode contribuir para uma compreensão mais consequente da mediação. Evidentemente que não se pretende assumir aqui uma forma de proselitismo laudatório da perspectiva antropológica. Trata-se apenas de, reconhecendo o grande potencial de desvelamento crítico que ela consigna, enfocar um expressivo autor que nela se inscreve. A esse respeito, Pierre Bourdieu, Jean-Claude Chamboredon e Jean-Claude Passeron observam que os antropólogos e os etnólogos seriam menos vulneráveis que os sociólogos relativamente à ilusão da evidência imediata ou à tentação de universalizar inconscientemente experiências

\footnotetext{
${ }^{8}$ A esse respeito, Jacques Commaille, ao desenvolver uma sociologia política do direito, pautada pelo diálogo entre as perspectivas do jurista, do sociólogo e do cientista social, também alude à importância de incorporar a visão do antropólogo. Cf. COMMAILLE, Jacques. À quoi nous sert le droit pour comprendre sociologiquement les incertitudes des sociétés contemporaines? SociologieS (Dossiers, Sociétés en mouvement), 07 mar. 2016, 2016, p. 12. Disponível em: $<$ http://sociologies.revues.org/5278 $>$. Acesso em: 5 de fevereiro de 2018.

${ }_{9}^{9}$ Acerca da necessidade de desenvolvimento de um programa interdisciplinar de pesquisa para a apreensão da mediação, ver: Cf. LE ROY, Étienne. La médiation mode d'emploi. Droit et Société, No. 29, 1995, p. 54.
} 
singulares. ${ }^{10}$ Em grande medida, isso se deve ao fato de que a técnica do dépaysement que caracteriza a análise antropológica a inclina naturalmente a apreender outros contextos que não apenas o ocidental, tornando-a, assim, em princípio, mais propensa a descentrar-se das referências empíricas e das categorias ocidentais. ${ }^{11}$ Aliás, é justamente por esse motivo que Eduardo Viveiros de Castro realça a centralidade que a pretensão de empreender uma crítica de caráter político-epistemológico da razão sociológica ocidental assume no discurso antropológico. ${ }^{12}$

Feitas essas considerações, convém observar que Étienne Le Roy, ao examinar as práticas, as formas e os procedimentos designados de mediação, os relaciona mais com o que ele denomina de juridicidade do que com o direito. Tendo isso em vista, será realizada, em primeiro lugar, uma breve alusão à distinção entre direito e juridicidade por ele proposta. Em seguida, será realçado o delineamento conceitual dado pelo autor à mediação, com especial ênfase na progressiva aquisição de centralidade que ela recebe em seu pensamento. Para explicitar esse movimento de aquisição de centralidade será examinado o modo como o autor concebia a mediação até a publicação do livro Le jeu des lois: Une anthropologie "dynamique" du Droit. ${ }^{13}$ A partir daí, tendo por horizonte a noção de

${ }^{10}$ BOURDIEU, Pierre; CHAMBOREDON, Jean-Claude; PASSERON, Jean-Claude. Le métier de sociologue. 5a ed. Berlin: Mouton de Gruyter, 2005, p. 100.

${ }^{11}$ Cf. LÉVI-STRAUSS, Claude. Anthropologie structurale deux. Paris: Plon, 1996, p. 320. A respeito, ver também: HÉNAFF, Marcel. Claude Lévi-Strauss et

l'anthropologie structurale. Paris: Belfond, 1991, p. 40-42. Acerca da preocupação com a questão da alteridade por parte da antropologia jurídica, ver, por exemplo:

ROULAND, Norbert. Anthropologie juridique. Paris: Presses Universitaires de France, 1988, p. 25.

12 Segundo o autor, "na medida em que muitos antropólogos concebem sua atividade como sendo primordialmente a de empreender uma crítica político-epistemológica da razão sociológica ocidental, esta posição ocupa um lugar central na disciplina". VIVEIROS DE CASTRO, Eduardo. A inconstância da alma selvagem e outros ensaios de antropologia. São Paulo, SP: Cosac \& Naify, 2002, p. 309. Acerca dessa pretensão crítica da antropologia, ver também: KANT DE LIMA, Roberto. Ensaios de Antropologia e de Direito: acesso à justiça e processos institucionais de administração de conflitos e produção da verdade jurídica em uma perspectiva comparada. Rio de Janeiro, RJ: Lumen Juris, 2008, p. 6.

${ }^{13}$ LE ROY, Étienne. Le jeu des lois: une anthropologie “dynamique” du Droit: avec des consignes et des conseils au "jeune joueur juriste". Paris: Librairie Générale de Droit et de Jurisprudence, 1999. 
juridicidade, será evidenciada a tese do autor acerca da mediação como um "conceito-pivô e dialogal da regulação global das sociedades". ${ }^{14}$ Finalmente, em termos conclusivos, procurar-se-á sublinhar o quanto uma consideração mais apurada dos aportes antropológicos pode contribuir para a compreensão dos regimes de juridicidade que caracterizam a complexa textura da regulação jurídica hodierna em meio à qual se inscreve a mediação. ${ }^{15}$

\section{Direito E JuRIDICIDADE NA TeORIA Do MultiJuRIDismo}

Inspirado pela pretensão de Michel Alliot de desenvolver uma ciência não etnocêntrica do direito, Étienne Le Roy procura elaborar uma abordagem complexa da regulação jurídica fundada, sobretudo, na

${ }^{14}$ Cf. LE ROY, Étienne. Place de la juridicité dans la médiation. Jurisprudence: Revue critique, No. 4 (La médiation. Entre renouvellement de l'offre de justice et droit), 2013, p. 200.

${ }^{15}$ A expressão regimes de juridicidade é utilizada por Étienne Le Roy, em sua obra $L a$ terre de l'autre: Une anthropologie des régimes d'appropriation foncière, para correlacionar, concretamente, a diversidade de tais regimes àquela que se refere aos distintos projetos de sociedade. Com isso, ele procura sublinhar a não universalidade das categorias fundantes das representações que estruturam a juridicidade ocidental, especialmente a distinção público/privado, estrategicamente abordada no contexto de sua análise relativa aos regimes de apropriação fundiária. LE ROY, Étienne. La terre de l'autre: Une anthropologie des régimes d'appropriation foncière. Paris: Librairie Générale de Droit et de Jurisprudence-Lextenso, 2011, p. 124 e ss. A respeito, ver também: LE ROY, Étienne. Des Communs 'à double révolution'. Droit et Société, No. 94, 2016, p. 603624. Em trabalho anterior, procurei imprimir à expressão regimes de juridicidade um sentido mais amplo. Assim, da mesma forma que o historiador François Hartog adota a expressão regimes de historicidade para analisar os diferentes modos de articulação das categorias do passado, presente e futuro (HARTOG, François. De l'histoire universelle à l'histoire globale? Expériences du temps. Le Débat: Écrire l'histoire du monde, No. 154, 2009, p. 55; HARTOG, François. Régimes d'historicité: Présentisme et expériences du temps. Paris: Seuil, 2012, p. 37-42), sugeri usar a expressão regimes de juridicidade para indicar a maneira pela qual ocorrem as relações, por vezes conflituosas e contraditórias, das formas de regulação caracterizadas por Le Roy como direito e como juridicidade. A respeito, ver: VILLAS BÔAS FILHO, Orlando. Juridicidade: uma abordagem crítica à monolatria jurídica enquanto obstáculo epistemológico. Revista da Faculdade de Direito da USP, Vol. 109, 2014, p. 314-317. 
alteridade e no descentramento das categorias jurídicas ocidentais. ${ }^{16}$ Assim, seria possível afirmar que o modelo analítico elaborado pelo autor, ao direcionar-se à apreensão de outros arranjos da regulação jurídica que mantêm significativa diferença relativamente àqueles que se expressam no contexto ocidental, permitir-lhe-ia a assunção de um viés intercultural de análise. Por conseguinte, a perspectiva formulada por Le Roy proporcionaria uma abordagem da regulação jurídica desvinculada de representações que, em termos positivistas, a reduzem à sua forma estatal de expressão. Segundo Christoph Eberhard ${ }^{17}$, a teoria do multijuridismo possibilitaria o abandono da visão monológica do fenômeno jurídico e o reconhecimento de que ele encontraria três fundamentos não redutíveis ou hierarquizáveis mutuamente. ${ }^{18}$ Conforme

\footnotetext{
${ }^{16}$ Cf. LE ROY, Étienne. Le jeu des lois: une anthropologie "dynamique" du Droit:
} avec des consignes et des conseils au "jeune joueur juriste". Paris: Librairie Générale de Droit et de Jurisprudence, 1999, p. 28. Le Roy, em diversos textos, sublinha a influência de Michel Alliot em seu pensamento. A respeito, ver, por exemplo: LE ROY, Étienne. La voie étroite de la médiation, entre les ordonnancements imposé et négocié de régulation des différends. Négociations: conflit, décision et délibération, Vol. 28, 2, 2017, p. 108; EBERHARD, Christoph. Le droit au miroir des cultures: pour une autre mondialisation. Paris: Librairie Générale de Droit et de Jurisprudence-Lextenso, 2010, p. 35. Sobre a discussão relativa à universalidade das categorias jurídicas ocidentais, ver: VILLAS BÔAS FILHO, Orlando. A questão da universalidade das categorias jurídicas ocidentais a partir da abordagem antropológica: nota sobre a discussão entre Max Gluckman e Paul Bohannan. Revista da Faculdade de Direito da USP, Vol. 110, 2015, p. 277-318.

${ }^{17}$ Cf. EBERHARD, Christoph. Le droit au miroir des cultures: pour une autre mondialisation. Paris: Librairie Générale de Droit et de Jurisprudence-Lextenso, 2010, p. 33 .

${ }^{18}$ Cf. LE ROY, Étienne. L'hypothèse du multijuridisme dans un contexte de sortie de modernité. In: Andrée Lajoie; Roderick MacDonald; Richard Janda; Guy Rocher (dir.). Théories et émergence du droit: pluralisme, surdétermination et effectivité. Bruxelles: Bruylant, 1998, p. 29-43. Para análises relativas à teoria do multijuridismo de Étienne Le Roy, ver, por exemplo: EBERHARD, Christoph. Towards an Intercultural Legal Theory: the Dialogical Challenge. Social \& Legal Studies, Vol. 10, 2, 2001, p. 171201; VANDERLINDEN, Jacques. Les Pluralismes juridiques. In: Edwige Rude-Antoine; Geneviève Chrétien-Vernicos (coords.). Anthropologies et droits: état des savoirs et orientations contemporaines. Paris: Dalloz, 2009, p. 46-52; VILLAS BÔAS FILHO, Orlando. A regulação jurídica para além de sua forma ocidental de expressão: uma abordagem a partir de Étienne Le Roy. Revista Direito \& Práxis, Vol. 6, 3, 2015, p. 159 - 
se verá a seguir, tais fundamentos - designados de normas gerais $e$ impessoais (NGI), modelos de conduta e de comportamento (MCC) e sistemas de disposições duráveis (SDD) - experimentariam vários modos de articulação e conformariam o campo do que é jurídico. ${ }^{19}$

195; VILLAS BÔAS FILHO, Orlando. Juridicidade: uma abordagem crítica à monolatria jurídica enquanto obstáculo epistemológico. Revista da Faculdade de Direito da USP, Vol. 109, 2014, p. 281-325; VILLAS BÔAS FILHO, Orlando. O direito de qual sociedade? Os limites da descrição sociológica de Niklas Luhmann acerca do direito a partir da crítica antropológica. In: Alberto Febbrajo; Fernando Rister Sousa Lima; Márcio Pugliesi (Orgs.). Sociologia do Direito: Teoria e Práxis. Curitiba, PR: Juruá, 2015, p. 337-366.

${ }^{19}$ A respeito, ver, especialmente: LE ROY, Étienne. Le jeu des lois: une anthropologie "dynamique" du Droit: avec des consignes et des conseils au "jeune joueur juriste". Paris: Librairie Générale de Droit et de Jurisprudence, 1999, p. 202. Após afirmar que lei, costume e habitus constituiriam os "fundamentos do Direito na França", Le Roy propõe substituir tais categorias com o intuito de desenvolver uma análise antropológica intercultural, por categorias descritivas gerais que lhes seriam correspondentes. Assim sendo, em sua proposta teórica, ocorre a substituição das categorias lei, costume e habitus pelas de "normas gerais e impessoais" (NGI), "modelos de condutas e de comportamentos" (MCC) e "sistemas de disposições duráveis" (SDD). Aqui, cabe ressaltar que a influência de Pierre Bourdieu sobre Étienne Le Roy é evidente, particularmente em virtude da crítica feita pelo primeiro ao que ele denomina de "juridismo" dos etnólogos, que consistiria na tendência de descrever o mundo social a partir da "linguagem da regra" e supor que a compreensão das práticas sociais seria obtida mediante a enunciação da regra explícita que supostamente as produziriam. Em Bourdieu, o habitus aparece como um sistema de disposições duráveis direcionado para a prática (caracterizado pela sua espontaneidade, vagueza e imprecisão) que constituiria o fundamento objetivo de condutas regulares. A indeterminação e a incerteza próprias do habitus são contrastadas, por Bourdieu, com "regramento expresso", que caracterizaria as condutas codificadas. Cf. BOURDIEU, Pierre. Habitus, code et codification. Actes de la Recherche en Sciences Sociales, Vol. 64, 1, 1986, p. 40-44. Acerca do campo jurídico, ver também: BOURDIEU, Pierre. La force du droit: éléments pour une sociologie du champ juridique. Actes de la Recherche en Sciences Sociales, Vol. 64, 1, 1986, p. 3-19; BOURDIEU, Pierre. Les juristes, gardiens de l'hypocrisie collective. In: François Chazel; Jacques Commaille (dir.). Normes juridiques et régulation sociale. Paris: Librairie Générale de Droit et de Jurisprudence, 1991, p. 95-99; BOURDIEU, Pierre. Sur l'État. Cours au Collège de France 1989-1992. Paris: Seuil, 2012. Para uma profunda análise da obra de Bourdieu no que concerne ao "campo jurídico", ver: GUIBENTIF, 
A partir de sua abordagem antropológica, Étienne Le Roy, refutando toda e qualquer definição a priori do que seria a regulação qualificável como jurídica, enfatiza a impossibilidade de se compreender o direito a partir de postulações preestabelecidas, posto que ele nada mais seria do que uma forma específica de concreção de um fenômeno mais amplo, designado pelo autor de juridicidade (juridicité). ${ }^{20}$ Logo, Le Roy propõe considerar a juridicidade como expressão de um domínio comum de regulação, no qual a experiência ocidental figura apenas como um folk

Pierre. Foucault, Luhmann, Habermas, Bourdieu: Une génération repense le droit. Paris: Librairie Générale de Droit et de Jurisprudence, 2010, p. 247-299. A respeito, ver também: GARCÍA VILLEGAS, Mauricio. On Pierre Bourdieu's Legal Thought. Droit et Société, No. 55-57, 2004, p. 57-70; LENOIR, Remi. Du droit au champ juridique. In: Louis Pinto; Gisèle Sapiro; Patrick Champagne (dir.). Pierre Bourdieu, sociologue. Paris: Fayard, 2004, p. 231-253. Le Roy analisa o conceito de habitus e especifica seu posicionamento diante do de Bourdieu. Cf. LE ROY, Étienne. Le jeu des lois: une anthropologie "dynamique" du Droit: avec des consignes et des conseils au "jeune joueur juriste". Paris: Librairie Générale de Droit et de Jurisprudence, 1999, p. 198-201; LE ROY, Étienne. La terre de l'autre: Une anthropologie des régimes d'appropriation foncière. Paris: Librairie Générale de Droit et de Jurisprudence-Lextenso, 2011, p. 127129. Por fim, no que tange às noções de campo e de habitus, ver, por exemplo: BOURDIEU, Pierre; CHARTIER, Roger. Le sociologue et l'historien. Paris: Raisons d'Agir, 2010, p. 73-88.

${ }^{20}$ Há uma tendência entre os antropólogos de grafar a palavra "direito" com "d" maiúsculo quando ela se refere ao "fenômeno jurídico" e com " $\mathrm{d}$ " minúsculo quando se trata do direito tal como se expressa concretamente no Ocidente. A respeito, ver, por exemplo: EBERHARD, Christoph. Towards an Intercultural Legal Theory: the Dialogical Challenge. Social \& Legal Studies, Vol. 10, 2, 2001, p. 181; EBERHARD, Christoph. Le droit au miroir des cultures: pour une autre mondialisation. Paris: Librairie Générale de Droit et de Jurisprudence-Lextenso, 2010, p. 23-24. A noção de juridicidade proposta por Étienne Le Roy permite superar essa distinção. Aliás, Étienne Le Roy considera que a utilização genérica do termo "direito" para a designação de todas as experiências da juridicidade é etnocêntrica. Cf. LE ROY, Étienne. Le pluralisme juridique aujourd'hui ou l'enjeu de la juridicité. In: Étienne Le Roy (dir.) Les Pluralismes Juridiques (Cahiers d'Anthropologie du Droit). Paris: Karthala, 2003, p. 12. A respeito, ver também: VANDERLINDEN, Jacques. Réseaux, pyramide et pluralisme ou regards sur la rencontre de deux aspirants-paradigmes de la science juridique. In: Jacques Vanderlinden. Les pluralismes juridiques. Bruxelles: Bruylant, 2013, p. 222. 
system, entre outros. ${ }^{21}$ Sua empreitada consiste em transcender a concepção de direito desenvolvida pelas sociedades ocidentais modernas em direção a outras tradições jurídicas que seriam igualmente legítimas, justificadas, pertinentes e racionais. Tais tradições, apesar de serem etnocentricamente desqualificadas como arcaicas, primitivas ou atrasadas, fariam parte da experiência contemporânea das formas de regulação social designadas como jurídicas, o que, por via de consequência, torna impossível fazê-las coincidir com o arranjo particular assumido pela juridicidade no contexto da modernidade ocidental. ${ }^{22}$

${ }^{21} \mathrm{Cf}$. LE ROY, Étienne. Le tripode juridique: Variations anthropologiques sur un thème de flexible droit. L'Année sociologique, Vol. 57, 2, 2007, p. 344; LE ROY, Étienne. Pour une anthropologie de la juridicité. In: Étienne Le Roy (dir.). Anthropologie et droit: intersections et confrontations (Cahiers d'anthropologie du droit). Paris: Karthala, 2004, p. 246. Para uma análise sociológica atenta à pluralidade das formas de regulação que, no contexto da sociedade mundializada, não coincidem mais com os critérios clássicos de juridicidade, ver: ARNAUD, André-Jean. La gouvernance: Un outil de participation. Paris: Librairie Générale de Droit et de Jurisprudence-Lextenso, 2014, p. 27 e ss. Sobre a governança, ver, por exemplo: VILLAS BÔAS FILHO, Orlando. A governança em suas múltiplas formas de expressão: o delineamento conceitual de um fenômeno complexo. Revista Estudos Institucionais, Vol. 2, 2, 2016, p. 670-706; VILLAS BÔAS FILHO, Orlando. O impacto da governança sobre a regulação jurídica contemporânea: uma abordagem a partir de André-Jean Arnaud. Revista Eletrónica Direito e Sociedade - REDES, Vol. 4, 1, 2016, p. 145-171; VILLAS BÔAS FILHO, Orlando. As transformações da regulação jurídica na sociedade contemporânea: a governança como paradigma. Revista Direito GV, Vol. 12, 1, 2016. Resenha de: ARNAUD, André-Jean. La gouvernance. Un outil de participation. Paris: Librairie Générale de Droit et de Jurisprudence-Lextenso, 2014, p. 251-259.

${ }^{22}$ Trata-se do que Étienne Le Roy designa de "lógica da subtração" e que Laura Nader e Ugo Mattei chamam de "argumento da falta" (lack argument). Cf. EBERHARD, Christoph. Towards an Intercultural Legal Theory: the Dialogical Challenge. Social \& Legal Studies, Vol. 10, 2, 2001, p. 174-175; MATTEI, Ugo; NADER, Laura. Plunder: when the rule of law is illegal. Oxford: Blackwell Publishing, 2008, p. 5/7/10/14-16/1922/65 e, especialmente, p. 67-76. Para uma ilustração dessa questão a partir da experiência africana, ver: LE ROY, Étienne. Les africains et l'institution de la justice: Entre mimétismes et métissages. Paris: Dalloz, 2004, p. VII e ss. Para uma análise do "argumento da falta" de Laura Nader e Ugo Mattei mediante um paralelo com a ideia de "lógica da subtração" de Étienne Le Roy e com o "critério da falta" apontado por Pierre Clastres, ver: VILLAS BÔAS FILHO, Orlando. A regulação jurídica para além de 
Ao salientar que as demais tradições jurídicas consignam experiências não redutíveis ao direito em sua configuração ocidental moderna e que, ademais, tais tradições são tão legítimas como a ocidental, Le Roy procura sublinhar a impossibilidade de projetar sobre elas as feições particulares assumidas pelo nosso direito como se estas contivessem em si a expressão da universalidade do fenômeno jurídico. ${ }^{23}$ A própria resistência de tais tradições às tentativas de ocidentalização que historicamente lhes foram impostas exprimiria a singularidade inextricável assumida pela juridicidade em seus múltiplos avatares, entre os quais o que se concretiza na experiência ocidental moderna. Apontar a legitimidade das diversas formas de manifestação da juridicidade e a impossibilidade de tomar uma delas como expressiva do fenômeno como um todo constitui um dos principais aportes do enfoque antropológico proposto por Le Roy, na medida em que explicita sua intenção de explorar o fenômeno jurídico em uma dimensão essencialmente intercultural. ${ }^{24}$

Assim, Étienne Le Roy procura ressaltar que a riqueza e a diversidade de experiências que compõem o fenômeno mais amplo da juridicidade não podem ser devidamente apreendidas mediante a sua redução ao modo pelo qual, historicamente, ocorreu a experiência ocidental, uma vez que ela, na verdade, manifesta apenas uma concepção concreta da juridicidade que a envolve. Visa-se com isso enfatizar que a pluralidade das formas de expressão da juridicidade não pode ser resolvida mediante a universalização impositiva de uma de suas experiências concretas, tal como a ocidental, em detrimento das demais, uma vez que esta remete a uma visão de mundo específica e não partilhada pelas outras culturas. Segundo Le Roy, a visão de mundo (cosmogonia) ocidental engendraria uma nomologia (nomologie), uma ciência da regra e também um culto à lei que seriam muito próprios de nossa tradição jurídica, mas que não

sua forma ocidental de expressão: uma abordagem a partir de Étienne Le Roy. Revista Direito \& Práxis, Vol. 6, 3, 2015, p. 164-165.

${ }^{23}$ Cf. LE ROY, Étienne. Le tripode juridique: Variations anthropologiques sur un thème de flexible droit. L'Année sociologique, Vol. 57, 2, 2007, p. 344 e 347. Para uma problematização da universalidade atribuída ao conceito de direito, ver: DUPRET, Baudouin. Réflexions sur le concept de droit à partir de quelques cas limites. Droit et Société, No. 94, 2016, p. 658-661.

${ }^{24}$ Cf. LE ROY, Étienne. Le jeu des lois: une anthropologie "dynamique" du Droit: avec des consignes et des conseils au "jeune joueur juriste". Paris: Librairie Générale de Droit et de Jurisprudence, 1999, p. 197-199. 
aparecem nas demais justamente porque as cosmogonias que as orientam são distintas. ${ }^{25}$

Étienne Le Roy também observa que as normas gerais e impessoais (NGI), os modelos de condutas e de comportamentos (MCC) e os sistemas de disposições duráveis (SDD), concebidos como três fundamentos da juridicidade, seriam inerentes a todas as maneiras de articulação assumidas por ela, inclusive a que se revela na tradição jurídica ocidental, motivo pelo qual não aceita reduzir o direito apenas à sua forma estatal de expressão. Portanto, segundo ele, a única diferença entre as diversas tradições jurídicas estaria no modo de articulação entre esses três fundamentos e seu respectivo meio de legitimação. Para o autor, as normas gerais e impessoais (NGI), ditas legais, apesar de serem privilegiadas na montagem experimentada pela juridicidade no quadro da experiência ocidental moderna, poderiam ser consideradas, metaforicamente, como a parte emergida de um iceberg jurídico, que compreenderia, na linha de flutuação, os modelos de condutas e de comportamentos (MCC) e os sistemas de disposições duráveis (SDD) que estariam amplamente imersos nas práticas sociais cotidianas. ${ }^{26}$

${ }^{25} \mathrm{Cf}$. LE ROY, Étienne. Le tripode juridique: Variations anthropologiques sur un thème de flexible droit. L'Année sociologique, Vol. 57, 2, 2007, p. 347-348. Conforme Le Roy, a "nomologia" seria expressão da "monolatria", ou culto do "um só" (culte du "un seul") que, segundo Paul Veyne, se associaria às origens do monoteísmo de nossa herança judaico-cristã. Sobre essa questão, ver: LE ROY, Étienne. Place de la juridicité dans la médiation. Jurisprudence: Revue critique, No. 4 (La médiation. Entre renouvellement de l'offre de justice et droit), 2013, p. 203. Caberia discutir essa questão à luz da secularização que, de Weber a Habermas, expressaria um traço fundamental da modernidade ocidental. Essa discussão, evidentemente, não é possível nos limites desta análise. A respeito, ver, por exemplo: BERIAIN, Josetxo. Representaciones colectivas y proyecto de modernidad. Barcelona: Anthropos, 1990; FOESSEL, Michaël; KERVÉGAN, Jean-François; REVAULT D'ALLONNES, Myriam (dir.). Modernité et sécularisation: Hans Blumenberg, Karl Löwith, Carl Schmitt, Leo Strauss. Paris: CNRS Éditions, 2007; GAUCHET, Marcel. Un monde désenchanté? Paris: Pocket, 2007. A respeito, ver: VILLAS BÔAS FILHO, Orlando. A regulação jurídica para além de sua forma ocidental de expressão: uma abordagem a partir de Étienne Le Roy. Revista Direito \& Práxis, Vol. 6, 3, 2015, p. 159-195; VILLAS BÔAS FILHO, Orlando. Juridicidade: uma abordagem crítica à monolatria jurídica enquanto obstáculo epistemológico. Revista da Faculdade de Direito da USP, Vol. 109, 2014, p. 281-325. ${ }^{26}$ Le Roy também designa essas três categorias descritivas de "macronormas", "mesonormas" e "micronormas", respectivamente. Cf. LE ROY, Étienne. Le jeu des lois: une anthropologie "dynamique" du Droit: avec des consignes et des conseils au 
Portanto, depois de expor essas três categorias gerais e ressaltar que elas conheceriam articulações distintas conforme se esteja em uma sociedade ou em outra, Étienne Le Roy propõe, à guisa de ilustração, um quadro comparativo que explicita as montagens experimentadas por esses três fundamentos da juridicidade em quatro grandes tradições jurídicas.

Quadro ilustrativo do modo pelo qual o "tripé jurídico" se articula em diferentes tradições jurídicas ${ }^{27}$

\begin{tabular}{cccc}
\hline Tradições jurídicas & Fundamento principal & Fundamento secundário & Fundamento terciário \\
\hline Ocidental/cristã & NGI & MCC & SDD \\
\hline Africana/animista & MCC & SDD & NGI \\
\hline Asiática/confuciana & SDD & MCC & NGI \\
\hline Árabe/muçulmana & NGI & SDD & MCC \\
\hline
\end{tabular}

Fonte: LE ROY, Étienne. Le jeu des lois: une anthropologie "dynamique" du Droit: avec des consignes et des conseils au "jeune joueur juriste". Paris: Librairie Générale de Droit et de Jurisprudence, 1999, p. 202.

“jeune joueur juriste”. Paris: Librairie Générale de Droit et de Jurisprudence, 1999, p. 201-202. Christoph Eberhard coloca reservas aos termos "macronormas", "mesonormas" e "micronormas". Cf. EBERHARD, Christoph. Penser le pluralisme juridique de manière pluraliste: Défi pour une théorie interculturelle du droit. In: Étienne Le Roy (dir.) Les Pluralismes Juridiques (Cahiers d'Anthropologie du Droit). Paris: Karthala, 2003, p. 58.

${ }^{27}$ Le Roy, expressando certo ceticismo em relação a grandes generalizações, ressalta que o quadro, designado como Variabilité des montages de la juridicité, tem interesse mais pedagógico do que científico. Cf. LE ROY, Étienne. Le jeu des lois: une anthropologie "dynamique" du Droit: avec des consignes et des conseils au "jeune joueur juriste". Paris: Librairie Générale de Droit et de Jurisprudence, 1999, p. 202-203. A respeito, ver: VILLAS BÔAS FILHO, Orlando. A regulação jurídica para além de sua forma ocidental de expressão: uma abordagem a partir de Étienne Le Roy. Revista Direito \& Práxis, Vol. 6, 3, 2015, p. 181; VILLAS BÔAS FILHO, Orlando. Juridicidade: uma abordagem crítica à monolatria jurídica enquanto obstáculo epistemológico. Revista da Faculdade de Direito da USP, Vol. 109, 2014, p. 305. 
Esse quadro visa explicitar as diversas articulações que podem ser assumidas entre os fundamentos da juridicidade conforme se esteja em uma ou em outra tradição jurídica. Assim, como enfatiza Étienne Le Roy, o quadro (que, ademais, não é exaustivo) serve para indicar a variabilidade de montagens da juridicidade..$^{28}$ Outrossim, ilustra concretamente a tese do autor de que esses três fundamentos da juridicidade apareceriam em todas as culturas ou tradições jurídicas, inclusive na ocidental, pois, segundo ele, é preciso notar que, mesmo no modo pelo qual se articula a juridicidade na tradição jurídica ocidental, coexistem normas gerais e impessoais, modelos de condutas e de comportamentos e sistemas de disposições duráveis. Destarte, nessa perspectiva, nem mesmo o direito ocidental visto como um avatar particular da juridicidade, ou seja, como uma espécie de folk law - poderia ser considerado coextensivo ao campo das normas gerais e impessoais. ${ }^{29}$ Conforme se verá a seguir, essa distinção entre direito e juridicidade é fundamental para a compreensão da análise que o autor faz da mediação. ${ }^{30}$

\section{O Que É MEDiação? UM DELINEAMENTO CONCEITUAl A PARTIR DE ÉTIENNE LE RoY}

Ao analisar a mediação, Étienne Le Roy ressalta, em primeiro lugar, que esta não poderia ser reduzida apenas a uma forma alternativa de resolução de conflitos. Segundo ele, a tendência imprópria, embora

${ }^{28}$ Cf. LE ROY, Étienne. Le jeu des lois: une anthropologie "dynamique" du Droit: avec des consignes et des conseils au "jeune joueur juriste". Paris: Librairie Générale de Droit et de Jurisprudence, 1999, p. 203.

${ }^{29}$ A respeito, o autor ressalta que "le droit est un avatar particulier de la juridicité, un folk law inhérent à la vision moderne de la société". LE ROY, Étienne. Les fondements de la socialisation juridique, entre droit et juridicité. In: Étienne Le Roy (dir.).

Pratiques citoyennes de droit (Cahiers d'anthropologie du droit). Paris: Karthala, 2011, p. 172.

${ }^{30}$ Cumpre desde logo notar que, na perspectiva de Le Roy, a sanção consiste no traço diacrítico comum ao direito e à juridicidade. Cf. LE ROY, Étienne. Place de la juridicité dans la médiation. Jurisprudence: Revue critique, No. 4 (La médiation. Entre renouvellement de l'offre de justice et droit), 2013, p. 204; LE ROY, Étienne. Les fondements de la socialisation juridique, entre droit et juridicité. In: Étienne Le Roy (dir.). Pratiques citoyennes de droit (Cahiers d'anthropologie du droit). Paris: Karthala, 2011, p. 176. 
plausível, de caracterizá-la desse modo decorreria da influência dos estudos norte-americanos que, na década de 1980, passaram a classificála como tal. ${ }^{31}$ Contudo, conforme ele procura frisar, especialmente a partir da década de 1990, a mediação teria se tornado progressivamente um meio de gestão administrativa (gestion managériale) consistente em uma maneira de se inscrever em uma interação, particularmente em um diálogo, com intuito de preparar uma solução compartilhável. Emergiriam daí dois de seus traços fundamentais: a) a busca pelo consenso, em lugar de uma decisão impositiva; b) seu vínculo com um projeto de vida que privilegia a adesão e a participação, em vez da reprodução mimética e dócil. Por tais motivos, segundo o autor, a mediação se tornaria, paulatinamente, um meio de responder à crise da democracia resgatando-lhe sua virtude participativa. ${ }^{32}$

De todo modo, Étienne Le Roy ressalta que sua produção acerca da mediação, cujo estatuto seria marginal no bojo de sua obra, poderia ser desdobrada em três momentos fundamentais, aos quais se refere em termos de modelos de análise. ${ }^{33} \mathrm{O}$ primeiro deles, em que se destaca o artigo

${ }^{31}$ De fato, como sublinham Thierry Delpeuch, Laurence Dumoulin e Claire de Galembert, os chamados "modos alternativos de resolução de conflito" (Alternative Dispute Resolution - ADR) ganharam grande visibilidade a partir de tal período.

DELPEUCH, Thierry; DUMOULIN, Laurence; GALEMBERT, Claire de. Sociologie du droit et de la justice. Paris: Armand Colin, 2014, p. 181. Para uma análise crítica da internacionalização das formas de ADR, ver: NADER, Laura. The life of the law: anthropological projects. Berkeley, CA: California University Press, 2002, p. 149-159. ${ }^{32}$ Cf. LE ROY, Étienne. Place de la juridicité dans la médiation. Jurisprudence: Revue critique, No. 4 (La médiation. Entre renouvellement de l'offre de justice et droit), 2013, p. 199.

${ }_{33}$ Cumpre notar que Étienne Le Roy considera o tema da mediação marginal no bojo de suas pesquisas e de sua produção teórica. Assim, observa que “je n'ai écrit qu'une vingtaine de textes sur la médiation, fort souvent en collaboration, édité un seul ouvrage $[\ldots]$, dirigé quatre rapports de recherches [...], donné quelques interviews $[\ldots]$, animé des formations [...] mais, à la différence de certains de mes amis, j'ai estimé qu'il ne fallait pas confondre théorie et pratique et qu'une distance devait être maintenue avec les passages à l'acte de médiation". LE ROY, Étienne. La voie étroite de la médiation, entre les ordonnancements imposé et négocié de régulation des différends. Négociations: conflit, décision et délibération, Vol. 28, 2, 2017, p. 107. Apesar disso, o autor é amplamente reconhecido entre teóricos das ciências sociais como uma referência na abordagem da mediação. À guisa de exemplo, ver: ARNAUD, André-Jean. Le droit trahi par la sociologie: Une pratique de l'histoire. Paris: 
intitulado Médiation mode d'emploi, publicado, em 1995, na revista Droit et société, pretende promover, sobretudo, a desconstrução da representação formalista e juridicizante que atrela a mediação ao campo do direito. ${ }^{34} \mathrm{O}$ segundo, marcado, especialmente, pelo artigo La médiation comme 'dialogie' entre les ordonnancements de régulation sociale, constante no livro Diversité culturelle et médiation: pour quelle Société?, por ele editado, em parceria com Carole Younès, em 2002, sublinha a progressiva transformação da mediação em um conceito central da regulação social contemporânea..$^{35} \mathrm{O}$ terceiro, expresso, principalmente, pelo artigo Place de la juridicité dans la médiation, que integra o $\mathrm{n}^{-} 4$ de Jurisprudence: revue critique, organizado por Gilda Nicolau, em 2013, mobiliza a hipótese da juridicidade, desenvolvida, sobretudo, a partir de 1999, com a publicação do livro Le jeu des lois: Une anthropologie 'dynamique' du Droit, para, a partir dela, propor uma melhor compreensão das práticas envolvidas na mediação. ${ }^{36}$

\section{A desconstrução da representação espontânea que atrela direito e mediação}

Desde seus primeiros escritos sobre a mediação, Étienne Le Roy já procurava evitar as definições convencionais que tendem a vinculá-la ao campo do direito. Assim, no citado artigo intitulado La médiation mode d'emploi, publicado no oㅡ 29 da revista Droit et Société, em 1995, no bojo de

Librairie Générale de Droit et de Jurisprudence, 1998, p. 42; ARNAUD, André-Jean; NOREAU, Pierre. The Sociology of Law in France: Trends and Paradigms. Journal of Law and Society, Vol. 25, 2, 1998, p. 275; GARCÍA VILLEGAS, Mauricio. Les pouvoirs du droit: analyse comparée d'études sociopolitiques du droit. Paris: Librairie Générale de Droit et de Jurisprudence-Lextenso, 2015, p. 281-282; GARCÍA VILLEGAS, Mauricio; LEJEUNE, Aude. La sociologie du droit en France: de deux sociologies à la création d'un projet pluridisciplinaire. Revue Interdisciplinaire d'Études Juridiques, Vol. 66, 1, 2011, p. 23-24.

${ }^{34}$ LE ROY, Étienne. La médiation mode d'emploi. Droit et Société, No. 29, 1995.

${ }^{35}$ LE ROY, Étienne. La médiation comme 'dialogie' entre les ordonnancements de régulation sociale. In: Carole Younès; Étienne Le Roy (dir.). Médiation et diversité culturelle: Pour quelle société? Paris: Karthala, 2002.

${ }^{36}$ Cf. LE ROY, Étienne. Place de la juridicité dans la médiation. Jurisprudence: Revue critique, No. 4 (La médiation. Entre renouvellement de l'offre de justice et droit), 2013, p. 195. 
um dossiê organizado por Jean-Pierre Bonafé-Schmitt, insistia na autonomia da mediação, de modo a concebê-la, já naquele momento, como um processo específico de regulação. ${ }^{37}$ Quase duas décadas mais tarde, no artigo Place de la juridicité dans la médiation, editado em 2013, em um volume de Jurisprudence: revue critique, o autor, referindo-se criticamente à tendência de inscrição da mediação no âmbito jurídico, retoma essa questão enfocando, especialmente, a expressiva análise de Michèle Guillaume-Hofnung, a qual, em seu entendimento, serviria de exemplo de uma acepção que, por ser portadora de forte conotação jurídica, não permitiria a apreensão da essência da mediação, sobretudo a que se desenvolve nos âmbitos social e comunitário. ${ }^{38}$ Assim, como a perspectiva dessa jurista é focalizada como o contraponto prioritário do exame que Le Roy pretende empreender acerca da mediação, será feita, a seguir, uma breve reconstrução de seus aspectos essenciais para que, a partir daí, sejam introduzidas as considerações deste autor. Evidentemente, trata-se de uma reconstrução bastante pontual, cujo intuito consiste apenas em explicitar alguns traços de uma abordagem que, apesar de sua aceitação generalizada entre os juristas, é considerada insuficiente por Étienne Le Roy.

Michèle Guillaume-Hofnung inicia sua análise enfatizando o caráter ilimitado que a mediação, como modo não jurisdicional de composição

${ }^{37}$ Afirmava, assim, que "la médiation et le droit proposent deux modes de régulation, chacun fondé sur la prévalence de certaines fins, donc autonomes tout en pouvant être combinés quand l'action sociale suppose des fins multiples, donc une combinaison de formes d'intervention. La médiation valorise, avons-nous vu, la recherche de l'adhésion de l'acteur à une solution la plus consensuelle possible, limitant en cela considérablement l'intervention de la tierce partie. [...] Plus prosaïquement, le droit évalue l'écart déjà observé entre des normes et les pratiques et détermine qui est en droit ou en faute par rapport à des règles du jeu déjà posées et susceptibles d'être invoquées dans une société régulée par l'État de droit. L'invocation de normes pour régler un conflit passé devant une instance jugée neutre parce qu'étrangère au conflit (le forum judiciaire) en vue d'obtenir une décision sanctionnant les conduites marginales ou déviantes sont caractéristiques de la manière dont le droit est généralement interprété par nos concitoyens". Cf. LE ROY, Étienne. La médiation mode d'emploi. Droit et Société, No. 29, 1995, p. 53-54.

${ }^{38}$ Cf. LE ROY, Étienne. Place de la juridicité dans la médiation. Jurisprudence: Revue critique, No. 4 (La médiation. Entre renouvellement de l'offre de justice et droit), 2013, p. 196. 
de conflitos, teria. ${ }^{39}$ Recobrindo, muitas vezes, práticas heterogêneas, o conceito de mediação apresentaria, segundo ela, um caráter pouco preciso, decorrente, fundamentalmente, de um uso prático que, não poucas vezes, não respeita sua figuração conceitual..$^{40}$ Conforme ressalta a autora, haveria uma significativa distância, para não dizer um abismo, entre o conceito e as práticas que pretendem ser expressão dele. Daí a necessidade de uma conceitualização precisa que, em seu entendimento, poderia ser esboçada nos seguintes termos:

[...] globalement la médiation se définit avant tout comme un processus de communication éthique reposant sur la responsabilité et l'autonomie des participants, dans lequel un tiers - impartial, indépendant, sans pouvoir décisionnel ou consultatif, avec la seule autorité que lui reconnaissent les médieurs - favorise par des entretiens confidentiels l'établissement, le rétablissement du lien social, la prévention ou le règlement de la situation en cause. [...] La médiation remplit une fonction fondamentale de rétablissement ou d'établissement de la communication. [...] La médiation est ternaire dans sa structure et dans son résultat. Sans l'élément tiers, la médiation n'existe pas. [...] Cette caractéristique fondamentale la distingue de la négociation et de la conciliation que peuvent faire l'économie du tiers. Il n'y a jamais de médiations directes, l'étymologie interdit l'éviction de l'intermédiaire. ${ }^{41}$

${ }^{39}$ Segundo Guillaume-Hofnung, “le champ de la méditation n’a pas de limite. Il englobe tous les secteurs de l'activité humaine, de la sphère la plus intime à la plus publique. La médiation concerne les personnes publiques aussi bien que les particuliers, les individus aussi bien que les groupes, les activités nationales et internationales". GUILLAUME-HOFNUNG, Michèle. La médiation. $7^{\mathrm{a}} \stackrel{\text { ed. Paris: }}{\text { end }}$ Presses Universitaires de France, 2015, p. 10.

${ }^{40}$ Cf. GUILLAUME-HOFNUNG, Michèle. La médiation. $7^{\text {a }}$ ed. Paris: Presses Universitaires de France, 2015, p. 10.

${ }^{41}$ GUILLAUME-HOFNUNG, Michèle. La médiation. $7^{a}$ ed. Paris: Presses Universitaires de France, 2015, p. 71. Uma definição análoga pode ser encontrada em GUILLAUME-HOFNUNG, Michèle. Le concept de médiation et l'urgence théorique. Les Cahiers du CREMOC, n. 35, 2002, p. 20. Acerca da difusão dessa perspectiva entre os juristas, ver: NICÁCIO, Camila Silva. La médiation: un projet de société? Aux origines du Forum de la société civile sur la médiation (FSCM). In: Étienne Le Roy (dir.). Pratiques citoyennes de droit (Cahiers d'anthropologie du droit). Paris: Karthala, 2011, p. 195. 
Desse modo, Michèle Guillaume-Hofnung, com o propósito de delinear conceitualmente a mediação, elenca os critérios que, a seu ver, seriam essenciais à sua definição: a) intervenção de um terceiro; b) independência do terceiro; c) neutralidade e imparcialidade; d) ausência de um poder institucional por parte do terceiro. Com base em tais critérios, a autora propugna a autonomia conceitual da mediação diante de outras formas de composição não jurisdicional de litígios, especialmente a conciliação, a transação e a arbitragem. Além disso, sustenta a sua autonomia em relação ao conflito. ${ }^{42}$ É nesse sentido que, referindo-se à obra de Jean-François Six, alude à mediação criadora, que tem por finalidade suscitar novos vínculos entre pessoas ou grupos; à mediação renovadora, que serviria à reativação de vínculos esgarçados; à mediação preventiva, cujo propósito seria evitar a eclosão de um conflito; e, finalmente, à mediação curativa, que auxiliaria a obtenção de uma solução para as partes em conflito. ${ }^{43}$ Não cabe aqui, evidentemente, incursionar em termos mais profundos pelo exame que Michèle Guillaume-Hofnung faz da mediação. O que importa notar é que, aos olhos de Étienne Le Roy, sua perspectiva teria um caráter juridicizante e, por isso, seria incapaz de apreender o fenômeno de modo mais consequente. ${ }^{44}$

A partir de uma significativa produção teórica a respeito da mediação, o autor de Le jeu des lois: Une anthropologie 'dynamique' du Droit desenvolveu, durante décadas, uma análise que a inscreve no horizonte

${ }^{42}$ Cf. GUILLAUME-HOFNUNG, Michèle. La médiation. $7^{\underline{a}}$ ed. Paris: Presses

Universitaires de France, 2015, p. 72 e ss. No mesmo sentido, ver: GUILLAUMEHOFNUNG, Michèle. Le concept de médiation et l'urgence théorique. Les Cahiers du CREMOC, n. 35, 2002, p. 22-23.

${ }^{43}$ Cf. GUILLAUME-HOFNUNG, Michèle. La médiation. $7^{\text {a }}$ ed. Paris: Presses Universitaires de France, 2015, p. 69. Sobre a perspectiva de Jean-François Six, ver também: NICÁCIO, Camila Silva. La médiation: un projet de société? Aux origines du Forum de la société civile sur la médiation (FSCM). In: Étienne Le Roy (dir.). Pratiques citoyennes de droit (Cahiers d'anthropologie du droit). Paris: Karthala, 2011, p. 194195.

${ }^{44}$ A respeito, Le Roy criticando a definição de Michèle Guillaume-Hofnung, contesta que "la médiation doive emprunter ses éléments de la définition à la justice, voire au droit". LE ROY, Étienne. Place de la juridicité dans la médiation. Jurisprudence: Revue critique, No. 4 (La médiation. Entre renouvellement de l'offre de justice et droit), 2013, p. 198. 
de sua reflexão antropológica acerca da regulação jurídica. ${ }^{45}$ Dentre seus primeiros textos dirigidos a essa questão, destaca-se o já referido artigo intitulado La médiation mode d'emploi. ${ }^{46}$ Nesse texto, Étienne Le Roy, partindo da distinção conceitual entre controvérsia, conflito e litígio, inicia seu exame tematizando a mediação a partir de quatro etapas, quais sejam: a) como prática de intervenção em uma controvérsia; b) como procedimento de gestão de um conflito; c) como procedimento parajudicial de composição de litígios; d) como ideologia da pacificação social, inclusive como projeto de sociedade..$^{47} \mathrm{Em}$ seguida, analisa-a, em termos críticos, como uma mercadoria e, finalmente, contrastando-a com o direito, procura desvelar sua especificidade como processo de regulação. ${ }^{48}$ Não se trata de fazer aqui uma reconstrução mais detalhada desse artigo. Contudo, uma breve alusão às suas ideias centrais permite uma excelente introdução ao estudo feito pelo autor sobre mediação.

Ao enfocar a mediação como prática de intervenção em uma controvérsia (pratique d'intervention dans un différend), Étienne Le Roy capitula os elementos que, em seu entendimento, seriam essenciais à sua definição: a) o mediador é um terceiro; b) a mediação interfere em uma comunicação que está bloqueada em virtude de uma oposição que as partes não logram superar ou relevar. Trata-se, assim, de uma oposição que está em aberto e que, apesar de as partes declararem pretender resolvê-la, elas não são capazes de fazê-lo por si próprias; c) a interposição do terceiro consiste, fundamentalmente, no estabelecimento das condições e dos meios para a produção de uma nova comunicação entre os protagonistas, motivo pelo qual a compreensão da disputa e das condições necessárias ao restabelecimento da comunicação são as principais tarefas do mediador; d) o acordo entre as partes não é imposto pelo mediador, ou seja, sua intervenção não engendra qualquer obrigação para as partes de executar o acordo, pois ela não é mais do que a restauração do vínculo social outrora esgarçado. ${ }^{49}$

${ }^{45}$ LE ROY, Étienne. Le jeu des lois: une anthropologie “dynamique" du Droit: avec des consignes et des conseils au "jeune joueur juriste". Paris: Librairie Générale de Droit et de Jurisprudence, 1999.

${ }^{46}$ LE ROY, Étienne. La médiation mode d'emploi. Droit et Société, No. 29, 1995.

${ }^{47}$ Cf. LE ROY, Étienne. La médiation mode d'emploi. Droit et Société, No. 29, 1995, p. 40-47.

${ }^{48}$ Cf. LE ROY, Étienne. La médiation mode d'emploi. Droit et Société, No. 29, 1995, p. 47-54.

${ }^{49}$ Aliás, é com base nisso que Étienne Le Roy diferencia a mediação da conciliação (na qual o terceiro pode propor uma solução à controvérsia) e da arbitragem (na qual a 
No que concerne à mediação como procedimento de gestão de um conflito (procédé de gestion d'un conflit), o autor, antes de mais nada, ressalta que o conflito não consiste apenas em uma oposição aberta, tal como ocorre com a controvérsia ou disputa (différend). Ele tem como característica o fato de também ser público, ou seja, conhecido por partes dos demais, ou até mesmo difundido midiaticamente. Assim, nesse caso, a intervenção do mediador não pode ser discreta ou secreta. Em tal situação, incumbiria a ele, na qualidade de terceiro interveniente, reunir, estruturalmente, quatro competências: a) gerir as relações entre as partes por meio de atitudes, da expressão de sentimentos e de competências capazes de promover o diálogo e fazer emergir um consenso; b) aparecer como uma figura de autoridade não em virtude de sua posição institucional ou de um mandato, mas em decorrência de sua neutralidade, objetividade e equidade; c) ter condições de apreender temporalidades comumente negligenciadas socialmente para poder restaurar as relações; d) privilegiar os fatos, e não as normas, concentrando seu exame mais nas práticas das partes do que nas explicações que elas fornecem. Logo, ao mediador, diferentemente do que ocorre com um magistrado, não cabe julgar, mas elucidar as condições que ensejaram o conflito e, a partir daí, abrir caminho para sua composição entre as partes. ${ }^{50}$

A mediação como procedimento parajudicial de resolução de litígios (procédure parajudiciaire de règlement des litiges) remete ao problema de sua relação com os procedimentos judiciais formais. Definindo o litígio como um conflito levado aos tribunais, Étienne Le Roy sustenta que, em tal situação, o recurso à mediação se implementa de duas maneiras: a) o Judiciário admite um tratamento paralelo de certos litígios por esferas judiciais e não judiciais conforme acordos entabulados pelas partes, o que imprime institucionalização a essa alternativa (forma comumente praticada nos EUA); b) o Judiciário - detentor da pretensão de monopólio da violência legítima - delega, sob a autoridade de um magistrado, a composição de certos litígios a instâncias locais, reservando-se o controle do exercício dessa delegação e preservando, além disso, a implementação das medidas propostas pela instância delegada (médiation à la française). ${ }^{51}$

solução se impõe como obrigatória em virtude de cláusulas prévias que vinculam as partes). Cf. LE ROY, Étienne. La médiation mode d'emploi. Droit et Société, No. 29, 1995, p. 41-42.

${ }^{50}$ Cf. LE ROY, Étienne. La médiation mode d'emploi. Droit et Société, No. 29, 1995, p. 43-44.

${ }^{51}$ Cf. LE ROY, Étienne. La médiation mode d'emploi. Droit et Société, No. 29, 1995, p. 44. 
Essa forma de mediação, recorrente no âmbito penal, se depara com quatro problemas fundamentais: a) dado que o mediador, ao se inscrever na instituição do Judiciário, não pode contrariar o direito, uma vez que está posto sob a autoridade hierárquica de um magistrado, sua função de terceiro neutro se esvazia diante de sua instrumentalização por parte do juiz que o subordina; $b$ ) todos os fatores implicados na administração da justiça, ao incidirem sobre a mediação, tendem a torná-la uma espécie de subjustiça (sous-justice); c) como decorrência, observa-se a perda de nitidez nas fronteiras que separam a mediação da conciliação e da arbitragem; d) na medida em que, nesse caso, a escolha do mediador é imposta pelo magistrado, a decisão deverá ser aceita pelas partes e formulada pelo magistrado ou, sob certas circunstâncias, pelo mediador. Por todos esses motivos, Le Roy questiona a adequação de se caracterizar como mediação uma situação que, na verdade, consiste em uma espécie de justiça negociada (justice negociée) ou justiça proposta (justice proposée).52

Cumpre notar que, no referido artigo, Étienne Le Roy também enfoca, criticamente, a mediação como ideologia da pacificação social e como mercadoria para, ao final, sublinhar, entre outras coisas, sua especificidade como modo de regulação. Ressalta, assim, que a mediação, ao valorizar a busca da adesão dos atores a uma solução que seja o mais consensual possível, limita drasticamente, por esse motivo, a intervenção do mediador como terceiro interveniente. Por conseguinte, rejeitando a associação da mediação a uma espécie de justice douce, nos termos definidos por Jean-Pierre Bonafé-Schmitt, sustenta o caráter inadequado do vocabulário jurídico para explicá-la. ${ }^{53}$

${ }^{52}$ Cf. LE ROY, Étienne. La médiation mode d'emploi. Droit et Société, No. 29, 1995, p. 44-55.

${ }^{53}$ Cf. BONAFÉ-SCHMITT, Jean-Pierre. Les modèles de médiation: modèles latins et anglo-saxons de médiation. Jurisprudence: Revue critique, No. 4 (La médiation. Entre renouvellement de l'offre de justice et droit), 2013; e LE ROY, Étienne. La médiation mode d'emploi. Droit et Société, No. 29, 1995, p. 48. Essa inadequação também será sublinhada em textos posteriores. Tal é especialmente o caso de uma expressiva passagem de seu livro Le jeu des lois: Une anthropologie "dynamique" du droit em que Le Roy, ao criticar Jean-Pierre Bonafé-Schmitt, ressalta que "les représentations de la justice n'offrent-elles rien de commun ni avec la palabre ni avec la médiation et c'est une confusion tragique qui ferait considérer la médiation comme 'une justice douce' et qui justifierait son contrôle par la justice dans le cadre de la médiation pénale. Violence faite à sa propre violence sous l'autorité d'un tiers, la médiation n'est jamais douce. Surtout, elle n'est pas une justice, même de proximité. Elle ne dit pas qui est en faute. Son objet est de concilier ou de réconcilier, de reconstruire le lien par le lieu de la 


\section{A progressiva aquisição de centralidade da mediação no pensamento de Étienne Le Roy: de forma de obtenção de compromissos negociados a conceito-pivô e dialogal da regulação global das sociedades}

Para se compreender a progressiva centralidade adquirida pelo conceito de mediação no pensamento de Étienne Le Roy, é necessário, em primeiro lugar, focalizar o que ele concebe e define em termos de ordenamento social (ordonnancement social) ${ }^{54}$ Essa noção, de acordo com o autor, remeteria à ideia de ordenação da sociedade segundo um dispositivo particular que implicaria, simultaneamente, um projeto e seus procedimentos. Com base nisso, distingue quatro tipos ideais de ordenamentos sociais: o ordenamento aceito, o ordenamento contestado, o

médiation". LE ROY, Étienne. Le jeu des lois: une anthropologie "dynamique" du Droit: avec des consignes et des conseils au "jeune joueur juriste". Paris: Librairie Générale de Droit et de Jurisprudence, 1999, p. 140. A respeito, ver também: LE ROY, Étienne. Place de la juridicité dans la médiation. Jurisprudence: Revue critique, No. 4 (La médiation. Entre renouvellement de l'offre de justice et droit), 2013, p. 198 e 205;

LE ROY, Étienne. La voie étroite de la médiation, entre les ordonnancements imposé et négocié de régulation des différends. Négociations: conflit, décision et délibération, Vol. 28, 2, 2017, p. 109; NICÁCIO, Camila Silva. La médiation: un projet de société? Aux origines du Forum de la société civile sur la médiation (FSCM). In: Étienne Le Roy (dir.). Pratiques citoyennes de droit (Cahiers d'anthropologie du droit). Paris: Karthala, 2011, p. 193; e GUILLAUME-HOFNUNG, Michèle. La médiation à la croisée des chemins, des responsabilités à prendre. Jurisprudence: Revue critique, No. 4 (La médiation. Entre renouvellement de l'offre de justice et droit), 2013, p. 136.

${ }^{54}$ A respeito, Le Roy afirma que " 1 'ordonnancement social est donc une mise en ordre de la société selon un dispositif particulier, impliquant à la fois un projet et des procédés. [...] L'ordonnancement est donc non seulement un rangement mais une mise en conformité selon un plan préexistant, avec une finalité, un objectif, un 'ordre' à respecter. Quand il ne s'agit pas seulement d'une pratique individuelle ou d'un comportement collectif mais de la mise en conformité d'un ensemble vaste et complexe qu'on appelle la société, on passe nécessairement à un niveau de contraintes qui appelle des régulations ad hoc. C'est là où émerge le Droit et c'est là où nous avons à interroger les juristes". LE ROY, Étienne. Le jeu des lois: une anthropologie "dynamique" du Droit: avec des consignes et des conseils au "jeune joueur juriste". Paris: Librairie Générale de Droit et de Jurisprudence, 1999, p. 145-146.

3 JOURNAL OF INSTITUTIONAL STUDIES 2 (2017) 
ordenamento imposto e o ordenamento negociado. ${ }^{55}$ Mobilizando essa distinção tipológica entre diferentes tipos de ordenamentos, o autor, em seus primeiros escritos, associava a mediação ao ordenamento negociado. Assim, no artigo La médiation mode d'emploi, esta era concebida, essencialmente, como uma forma negociada de resolução de um problema. ${ }^{56}$ Em seguida, no livro Le jeu des lois: Une anthropologie 'dynamique' du Droit, a mediação passa a ser considerada um dos instrumentos mais importantes do ordenamento negociado. ${ }^{57}$ A respeito, cumpre notar que Norbert Rouland fundamenta sua análise acerca dos "procedimentos alternativos de resolução de conflitos" nos "tipos ideais de ordenamento social" propostos por Étienne Le Roy. ${ }^{58}$ Aliás, no quadro

${ }^{55}$ Cf. LE ROY, Étienne. Le jeu des lois: une anthropologie “dynamique” du Droit: avec des consignes et des conseils au "jeune joueur juriste". Paris: Librairie Générale de Droit et de Jurisprudence, 1999, p. 149-156. Cumpre notar que, em seus primeiros escritos, Étienne Le Roy utilizava as expressões "ordem aceita", "ordem negociada", "ordem imposta" e "ordem contestada" para se referir às diversas formas de "ordens normativas". Cf. LE ROY, Étienne. La conciliation et les modes précontentieux de règlement des conflits. Bulletin de liaison du laboratoire d'anthropologie juridique de Paris, No. 12, 1987, p. 39-50. Essa distinção foi posteriormente retomada, pelo autor, especialmente no livro intitulado Le jeu des lois. Une anthropologie "dynamique" du Droit. LE ROY, Étienne. Le jeu des lois: une anthropologie "dynamique" du Droit: avec des consignes et des conseils au "jeune joueur juriste". Paris: Librairie Générale de Droit et de Jurisprudence, 1999. Contudo, a partir dessa obra, Le Roy, inspirando-se no termo italiano ordinamento, passou a preferir as expressões "ordenamento imposto", "ordenamento negociado", "ordenamento aceito" e "ordenamento contestado" (ordonnancements imposé, négocié, accepté et contesté). A respeito, ver: LE ROY, Étienne. La voie étroite de la médiation, entre les ordonnancements imposé et négocié de régulation des différends. Négociations: conflit, décision et délibération, Vol. 28, 2, 2017, p. 108.

${ }^{56}$ Cf. LE ROY, Étienne. La médiation mode d'emploi. Droit et Société, No. 29, 1995, p. 39.

${ }^{57}$ Cf. LE ROY, Étienne. Le jeu des lois: une anthropologie “dynamique" du Droit: avec des consignes et des conseils au "jeune joueur juriste". Paris: Librairie Générale de Droit et de Jurisprudence, 1999, p. 350.

${ }^{58}$ Cf. ROULAND, Norbert. Anthropologie juridique. Paris: Presses Universitaires de France, 1988, p. 446-448; ROULAND, Norbert. L'anthropologie juridique. $2^{\mathrm{a}}$ ed. Paris: Presses Universitaires de France, 1995, p. 84-85; e ROULAND, Norbert. Nos confins do Direito: Antropologia Jurídica da modernidade. Trad. Maria Ermantina de Almeida Prado Galvão. São Paulo, SP: Martins Fontes, 2003, p. 135-145. 
tipológico, veiculado no livro Anthropologie juridique, a mediação aparece situada justamente entre o ordenamento aceito e o ordenamento negociado. ${ }^{59}$

${ }^{59}$ Vale notar que Rouland utiliza o termo "ordem" (ordre) que, como ressaltado, a partir do livro Le jeu des lois: Une anthropologie dynamique du droit, é substituído por "ordenamento" (ordonnancement). Cf. ROULAND, Norbert. Anthropologie juridique. Paris: Presses Universitaires de France, 1988, p. 447; e LE ROY, Étienne. Le jeu des lois: une anthropologie "dynamique" du Droit: avec des consignes et des conseils au “jeune joueur juriste". Paris: Librairie Générale de Droit et de Jurisprudence, 1999. No Brasil, esse quadro inspirou as análises de José Eduardo Faria acerca dos "tipos de ordens normativas e suas práticas judiciais". Cf. FARIA, José Eduardo. Estado, Sociedade e Direito. In: José Eduardo Faria; Rolf Kuntz. Qual o futuro dos direitos? Estado, mercado e justiça na reestruturação capitalista. São Paulo, SP: Max Limonad, 2002, p. 75; FARIA, José Eduardo. Sociologia Jurídica: Direito e Conjuntura. 2ª ed. São Paulo, SP: Saraiva, 2010, p. 46-47. 
Quadro 1 - Tipos ideais de ordens normativas

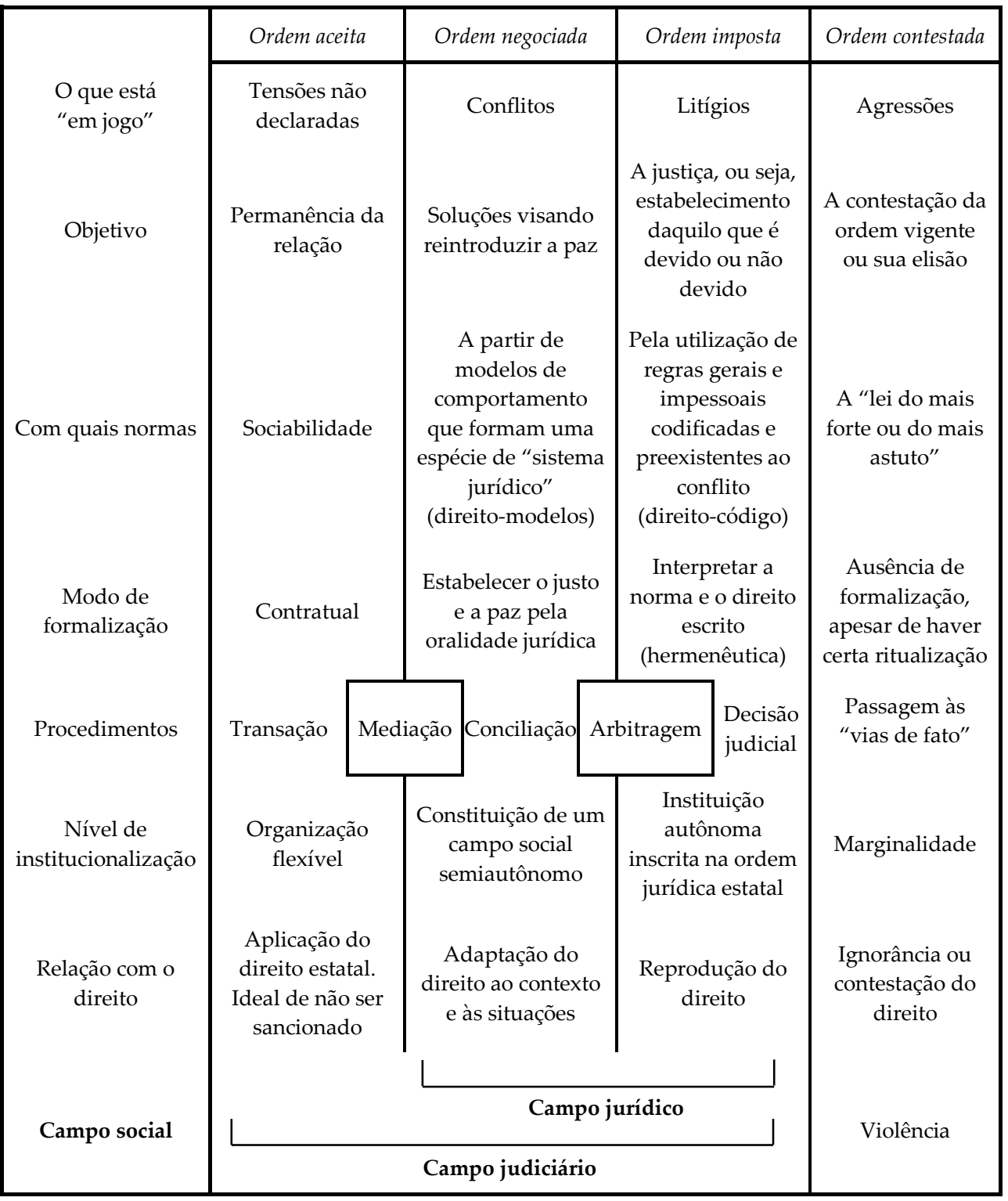

Fonte: ROULAND, Norbert. Anthropologie juridique. Paris: Presses Universitaires de France, 1988, p. 447.60

${ }^{60}$ Comentando esse quadro, Étienne Le Roy, em um e-mail que me enviou em 4 de janeiro de 2017, faz a seguinte observação: “le tableau des types idéaux indique la place de la médiation entre les ordonnancements négocié et accepté, ce qui me parait 
Contudo, a partir do início dos anos 2000, a mediação começa a adquirir progressiva centralidade no pensamento de Étienne Le Roy, que passou a considerá-la um conceito-pivô e dialogal da regulação global das sociedades. ${ }^{61}$ Portanto, conforme observam Carole Younès e Jackie Loteteca - referindo-se ao artigo intitulado La médiation comme 'dialogie' entre les ordonnancements de régulation sociale, publicado em 2002 -, Le Roy teria passado a identificar a mediação como uma espécie de dialogia não apenas entre os atores sociais, mas também entre os ordenamentos sociais. ${ }^{62}$ De fato, em tal artigo, esse autor afirma que a mediação não se inscreveria apenas no âmbito do ordenamento negociado. De acordo com ele, em virtude de empréstimos e mestiçagens, a mediação teria, progressivamente, se associado aos outros ordenamentos sociais (aceito, contestado e imposto), motivo pelo qual teria deixado de ser uma forma alternativa de resolução de conflitos para se tornar um conceito de base para a garantia da boa governança em escala nacional e internacional, engatando-se, assim, à globalização. Nesse sentido, a mediação seria o reflexo de uma organização social complexa. ${ }^{63} \mathrm{O}$ esquema a seguir, proposto

toujours justifié selon la logique des types idéaux. Mais l'expérience française, et plutôt une judiciarisation qu'une juridicisation, lui font occuper la place de l'arbitrage dans le tableau, lequel reste ainsi limité aux échanges commerciaux". O quadro, ademais, parece inverter o âmbito de abrangência do "campo jurídico" e do "campo judiciário", fazendo com que o segundo englobe o primeiro, quando, na verdade, se trata do contrário.

${ }^{61}$ Cf. LE ROY, Étienne. Place de la juridicité dans la médiation. Jurisprudence: Revue critique, No. 4 (La médiation. Entre renouvellement de l'offre de justice et droit), 2013, p. 200.

${ }^{62}$ Cf. YOUNÈS, Carole; LOTETEKA, Jackie. La place du tiers dans la médiation. In: Christoph Eberhard; Geneviève Vernicos (dir.). La quête anthropologique du droit: Autour de la démarche d'Étienne Le Roy. Paris: Karthala, 2006, p. 340.

${ }^{63}$ Cf. LE ROY, Étienne. La médiation comme 'dialogie' entre les ordonnancements de régulation sociale. In: Carole Younès; Étienne Le Roy (dir.). Médiation et diversité culturelle: Pour quelle société? Paris: Karthala, 2002, p. 86. Sobre a questão da governança, ver: ARNAUD, André-Jean. La gouvernance: Un outil de participation. Paris: Librairie Générale de Droit et de Jurisprudence-Lextenso, 2014; VILLAS BÔAS FILHO, Orlando. A governança em suas múltiplas formas de expressão: o delineamento conceitual de um fenômeno complexo. Revista Estudos Institucionais, Vol. 2, 2, 2016, p. 670-706; VILLAS BÔAS FILHO, Orlando. O impacto da governança sobre a regulação jurídica contemporânea: uma abordagem a partir de André-Jean Arnaud. Revista Eletrónica Direito e Sociedade - REDES, Vol. 4, 1, 2016, p. 145-171. 
originalmente no texto supracitado e reproduzido, uma década depois, no artigo intitulado Place de la juridicité dans la médiation, expressa essa progressiva centralidade atribuída à mediação por Étienne Le Roy, mediante seu deslocamento para a posição de um conceito-pivô e dialogal da regulação global das sociedades. ${ }^{64}$

${ }^{64}$ Cf. LE ROY, Étienne. Place de la juridicité dans la médiation. Jurisprudence: Revue critique, No. 4 (La médiation. Entre renouvellement de l'offre de justice et droit), 2013, p. 200. Esse esquema ilustra bem a aquisição de progressiva centralidade, por parte da mediação, no pensamento de Étienne Le Roy. A respeito, ver também: LE ROY, Étienne. La médiation comme 'dialogie' entre les ordonnancements de régulation sociale. In: Carole Younès; Étienne Le Roy (dir.). Médiation et diversité culturelle: Pour quelle société? Paris: Karthala, 2002, p. 86; YOUNÈS, Carole; LOTETEKA, Jackie. La place du tiers dans la médiation. In: Christoph Eberhard; Geneviève Vernicos (dir.). La quête anthropologique du droit: Autour de la démarche d'Étienne Le Roy. Paris: Karthala, 2006, p. 340-341. Para outras análises acerca da mediação, a partir do ângulo antropológico, ver, por exemplo: ASSIER-ANDRIEU, Louis. O Direito nas Sociedades Humanas. Trad. Maria Ermantina Galvão. São Paulo, SP: Martins Fontes, 2000, p. 180 e ss.; FAGET, Jacques. Éloge du fluide: Une lecture sociopolitique de la médiation. In: Christoph Eberhard; Geneviève Vernicos (dir.). La quête anthropologique du droit: Autour de la démarche d'Étienne Le Roy. Paris: Karthala, 2006, p. 297-310; FAGET, Jacques. Les vies écartelées de la médiation. Jurisprudence: Revue critique, No. 4 (La médiation. Entre renouvellement de l'offre de justice et droit), 2013, p. 143-150; MacDONALD, Roderick; SAVOIE, Pierre-Olivier. Une phénoménologie des modes alternatifs de résolution des conflits: résultat, processus et symbolisme. In: Christoph Eberhard; Geneviève Vernicos (dir.). La quête anthropologique du droit: Autour de la démarche d'Étienne Le Roy. Paris: Karthala, 2006, p. 275-295; NICÁCIO, Camila Silva. Direito e mediação de conflitos: entre metamorfose da regulação social e administração plural da justiça. Revista da Faculdade de Direito da UFMG, No. 59, 2011; NICÁCIO, Camila Silva. Médiation face à la reconfiguration de l'enseignement et de la pratique du droit: défis et impasses à la socialisation juridique. Jurisprudence: Revue critique, No. 4 (La médiation. Entre renouvellement de l'offre de justice et droit), 2013, p. 171191; NICÁCIO, Camila Silva. La médiation: un projet de société? Aux origines du Forum de la société civile sur la médiation (FSCM). In: Étienne Le Roy (dir.). Pratiques citoyennes de droit (Cahiers d'anthropologie du droit). Paris: Karthala, 2011, p. 193212; NICOLAU, Gilda. Entre médiation et droit, les enjeux d'une bonne intelligence. Jurisprudence: Revue critique, No. 4 (La médiation. Entre renouvellement de l'offre de justice et droit), 2013, p. 209-235; NICOLAU, Gilda. Éprouver le droit, instituer la vie: Médiation et cadre judiciaire. In: Christoph Eberhard; Geneviève Vernicos (dir.). La quête anthropologique du droit: Autour de la démarche d'Étienne Le Roy. Paris: 


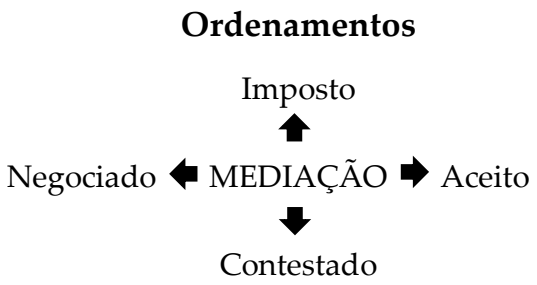

Fonte: LE ROY, Étienne. Place de la juridicité dans la médiation. Jurisprudence: Revue critique, No. 4 (La médiation. Entre renouvellement de l'offre de justice et droit), 2013, p. 200.

Consoante Étienne Le Roy, esse esquema teria o mérito de desvelar as ambiguidades de uma mediação que, deixando de ter uma função adstrita ao âmbito do ordenamento negociado, começaria a ser cada vez mais utilizada no plano do ordenamento imposto (ou seja, da Justiça) para promover a aceitação da intervenção do magistrado ou de uma decisão judicial. ${ }^{65}$ Para sustentar essa espécie de mestiçagem de ordenamentos, ensejada pela mediação, o autor enfoca a implementação dessa experiência na esfera penal, no contexto midiático e, finalmente, a partir do que ele designa de intermediação cultural.66 Em meio a essas experiências, a última é particularmente significativa e serve para ilustrar as pesquisas e as intervenções desenvolvidas, a partir de meados da década de 1990, pelo Laboratoire d'Anthropologie Juridique de Paris (LAPJ),

Karthala, 2006, p. 311-331; ROULAND, Norbert. Nos confins do Direito:

Antropologia Jurídica da modernidade. Trad. Maria Ermantina de Almeida Prado Galvão. São Paulo, SP: Martins Fontes, 2003, p. 127-130; SCHRITZMEYER, Ana Lúcia

Pastore. Anthropologie, droit et médiation au Brésil: un champ dialogique en construction. Jurisprudence: Revue critique, No. 4 (La médiation. Entre renouvellement de l'offre de justice et droit), 2013, p. 59-69.

${ }^{65}$ Cf. LE ROY, Étienne. Place de la juridicité dans la médiation. Jurisprudence: Revue critique, No. 4 (La médiation. Entre renouvellement de l'offre de justice et droit), 2013, p. 200.

${ }^{66} \mathrm{~A}$ respeito, o autor afirma que "je vais ici illustrer brièvement le métissage des ordonnancements et donc de la médiation qui en résulte, en prenant successivement les exemples de la médiation pénale, de la médiation de la presse et de l'intermédiation culturelle". LE ROY, Étienne. La médiation comme 'dialogie' entre les ordonnancements de régulation sociale. In: Carole Younès; Étienne Le Roy (dir.). Médiation et diversité culturelle: Pour quelle société? Paris: Karthala, 2002, p. 86. 
no Tribunal pour Enfants de Paris (TEF). ${ }^{67}$ Não cabe, evidentemente, fazer uma digressão mais ampla acerca dessa questão neste artigo. Entretanto, algumas observações pontuais se fazem necessárias para explicitar a importância da mediação diante da diversidade cultural.

Tendo por horizonte tais pesquisas e intervenções, Étienne Le Roy propõe um deslocamento conceitual que, embora sutil, é muito significativo e não pode ser desconsiderado. Trata-se da substituição da designação mediação intercultural por intermediação cultural. ${ }^{68}$ Para além de uma mera alteração de nomenclatura, essa mudança visa exprimir, em primeiro lugar, a transformação do estatuto do terceiro interveniente no âmbito da intermediação, pois este, na qualidade de intermediador, deixa de ser o terceiro neutro da mediação. ${ }^{69}$ Em segundo lugar, cuida-se também de sublinhar o caráter dialógico assumido pela intermediação, pois nesta, diferentemente do que ocorre com a mediação, não se promove a resolução do conflito a partir de uma situação em que vige a liberdade de aceitação, por parte dos mediados, relativamente ao processo e à solução, mas criam-se as condições para um diálogo que, entretanto, não se reduz apenas a uma troca de pontos de vista, mas que se realiza na apreensão recíproca das lógicas mobilizadas pelos atores implicados. É por isso que,

${ }^{67}$ Essa experiência é amplamente enfocada pelo capítulo 34 do livro Le jeu des lois em que o autor, a partir de uma perspectiva que contrasta França e Canadá, analisa a Justiça e a mediação penal. Cf. LE ROY, Étienne. Le jeu des lois: une anthropologie "dynamique" du Droit: avec des consignes et des conseils au "jeune joueur juriste". Paris: Librairie Générale de Droit et de Jurisprudence, 1999, p. 341 e ss. A respeito, ver também: LE ROY, Étienne. Les africains et l'institution de la justice: Entre mimétismes et métissages. Paris: Dalloz, 2004, p. 240-249.

68 A respeito, Le Roy ressalta que "aucun d'entre nous ne dispose naturellement d'une connaissance de l'autre qui satisfasse l'exigence de rencontre des cultures lorsque la distance ou l'étrangeté opposent des stéréotypes ou des préjugés. Il faut nécessairement entrer en dialogue et cette démarche est généralement dénommée 'médiation interculturelle'. Pourtant, lorsque ce dialogue des cultures a pour cadre l'Institution de la Justice, la démarche de médiation doit être adaptée à son contexte et à ses enjeux. C'est la raison pour laquelle nous avons choisi, et pour éviter tout malentendu sur la démarche et ses objectifs, d'adapter la terminologie et de faire passer le préfixe 'inter' de l'adjectif 'culturel' au substantif 'médiation'". LE ROY, Étienne. Les africains et l'institution de la justice: Entre mimétismes et métissages. Paris: Dalloz, 2004, p. 241.

${ }^{69}$ Cf. LE ROY, Étienne. Place de la juridicité dans la médiation. Jurisprudence: Revue critique, No. 4 (La médiation. Entre renouvellement de l'offre de justice et droit), 2013, p. 201. 
no âmbito da intermediação, o diatopismo se afigura como condição necessária à concretização do diálogo.$^{70}$ Conforme observam Carole Younès e Jackie Loteteka, o caráter diatópico que perpassa a intermediação implica a consideração da perspectiva cultural a partir da qual se fala e a dos interlocutores, além de suas formas de racionalidade, para que, a partir daí, possa se concretizar o diálogo. ${ }^{71}$

\section{Mediação e juridicidade}

Em seus trabalhos mais recentes, Étienne Le Roy, procurando aprofundar a desvinculação da mediação de suas referências jurídicas e judiciárias, propõe sua inscrição no âmbito do que denomina de juridicidade, entendendo por tal um domínio comum de regulação caracterizável como jurídico em virtude de seu caráter obrigatório e, portanto, sancionável. ${ }^{72}$ Desse modo, a teoria do multijuridismo de Étienne Le Roy permitiria, conforme mencionado, a superação de uma visão monológica do fenômeno jurídico (por ele aludido como Direito com $d$ maiúsculo) e o reconhecimento de seu caráter de tripé, ou seja, o fato de que ele apresentaria três fundamentos não redutíveis ou

${ }^{70}$ Referindo-se a uma comunicação realizada, em 2002, por Étienne Le Roy ao Dispositif Expert Régional Pour Adolescents en Difficultés (DERPAD), Carole Younès e Jackie Loteteka precisam o sentido do termo diálogo: "Dia logue du grec ancien en associant le préfixe dia (entre/traverser en latin trans) et le substantif logos (parole, discours, connaissance et culture, logique par opposition à praxis, l'action) il s'agit [de] dépasser la tension qu'induit l'étrangeté, la dissemblance". YOUNÈS, Carole; LOTETEKA, Jackie. La place du tiers dans la médiation. In: Christoph Eberhard; Geneviève Vernicos (dir.). La quête anthropologique du droit: Autour de la démarche d'Étienne Le Roy. Paris: Karthala, 2006, p. 342.

${ }^{71}$ Cf. YOUNÈS, Carole; LOTETEKA, Jackie. La place du tiers dans la médiation. In: Christoph Eberhard; Geneviève Vernicos (dir.). La quête anthropologique du droit:

Autour de la démarche d'Étienne Le Roy. Paris: Karthala, 2006, p. 342.

72 Desse modo, Le Roy sustenta que "en libérant la médiation de ses références juridiques et judiciaires 'modernes' tout en l'inscrivant dans une lecture de la juridicité d'une société dans un monde irrémédiablement complexe peut être une bonne approche". LE ROY, Étienne. La voie étroite de la médiation, entre les ordonnancements imposé et négocié de régulation des différends. Négociations: conflit, décision et délibération, Vol. 28, 2, 2017, p. 112. 
hierarquizáveis mutuamente: normas gerais e impessoais (NGI); modelos de conduta e de comportamento (MCC); e sistemas de disposições duráveis (SDD).

Para realizar a análise do que designa de tripé jurídico (tripode juridique), Étienne Le Roy parte de uma abordagem antropológica da obra Flexible Droit de Jean Carbonnier. ${ }^{73}$ Logo no primeiro capítulo da referida obra, em que são esboçadas as hipóteses fundamentais para uma sociologia teórica do direito, Carbonnier, depois de proceder a um breve exame do que denomina hipótese do pluralismo jurídico, propõe dois teoremas fundamentais para a sociologia jurídica. $\mathrm{O}$ primeiro consiste na afirmação de que o direito seria maior do que suas fontes formais. $\mathrm{O}$ segundo sustenta que o direito seria menor que o conjunto das relações entre os homens. ${ }^{74} \mathrm{~A}$ esses dois teoremas, propostos por Carbonnier para fundamentar sua sociologia jurídica, Le Roy agrega um terceiro que, em seu entendimento, permitiria descentrar a análise de sua referência à experiência ocidental do direito. Esse terceiro teorema consiste na postulação de que a juridicidade é mais ampla que a concepção do direito desenvolvida nas sociedades ocidentais de modo a abarcá-la. ${ }^{75}$

Por conseguinte, recuperando os dois teoremas propostos por Carbonnier para fundamentar a sociologia jurídica, Étienne Le Roy introduz a questão da juridicidade como algo que figuraria, por assim

${ }^{73} \mathrm{Cf}$. LE ROY, Étienne. Le tripode juridique: Variations anthropologiques sur un thème de flexible droit. L'Année sociologique, Vol. 57, 2, 2007, p. 344-345; e CARBONNIER, Jean. Flexible droit: pour une sociologie du droit sans rigueur. $10^{\mathrm{a}}$ ed. Paris: Librairie Générale de Droit et de Jurisprudence, 2001.

${ }^{74}$ Os dois teoremas de Carbonnier são os seguintes: "le droit est plus grand que les sources formelles du droit" e "le droit est plus petit que l'ensemble des relations entre les hommes". CARBONNIER, Jean. Flexible droit: pour une sociologie du droit sans rigueur. $10^{a}$ ed. Paris: Librairie Générale de Droit et de Jurisprudence, 2001, p. 21-24. Acerca da "hipótese do pluralismo jurídico", ver também: CARBONNIER, Jean. Sociologie juridique. $2^{\mathrm{a}}$ ed. Paris: Presses Universitaires de France, 2008, p. 356-374. Para uma excelente análise do pensamento de Carbonnier, ver: ARNAUD, André-Jean. Jean Carbonnier: Un juriste dans la cité. Paris: Librairie Générale de Droit et de Jurisprudence-Lextenso, 2012.

${ }^{75} \mathrm{Cf}$. LE ROY, Étienne. Le tripode juridique: Variations anthropologiques sur un thème de flexible droit. L'Année sociologique, Vol. 57, 2, 2007, p. 345; LE ROY, Étienne. Place de la juridicité dans la médiation. Jurisprudence: Revue critique, No. 4 (La médiation. Entre renouvellement de l'offre de justice et droit), 2013, p. 203; e LE ROY, Étienne. LE ROY, Étienne. Autonomie du droit, hétéronomie de la juridicité. In: Rodolfo Sacco (ed.). Le nuove ambizioni del sapere del giurista: antropologia giuridica e traduttologia giuridica. Roma: Accademia Nazionale dei Lincei, 2009, p. 100. 
dizer, no ponto cego de uma perspectiva que, como o autor de Flexible Droit, expressaria um referencial teórico circunscrito à tradição jurídica ocidental. ${ }^{76}$ Ao descentrar-se da concepção ocidental de direito transcendendo, assim, as balizas que circunscrevem a obra de Carbonnier -, Le Roy reafirma a ideia de que a juridicidade manifesta um domínio comum de regulação, no qual a experiência ocidental figura apenas como um folk system, entre outros. Portanto, sua empreitada consiste em transcender a concepção de direito desenvolvida pelas sociedades ocidentais modernas em direção a outras tradições jurídicas igualmente legítimas, justificadas, pertinentes e racionais. Tais tradições, apesar de serem etnocentricamente desqualificadas como arcaicas, primitivas ou atrasadas, fariam parte da experiência contemporânea das formas de regulação social designadas como jurídicas, o que, por via de consequência, torna impossível fazê-las coincidir com o arranjo particular assumido pela juridicidade no contexto da modernidade ocidental. ${ }^{77}$

Não cabe reconstruir aqui a crítica que Étienne Le Roy endereça à perspectiva de Jean Carbonnier. ${ }^{78}$ Cumpre apenas sublinhar que é a partir dela que ele desenvolve sua crítica à monolatria como obstáculo epistemológico para uma adequada compreensão da regulação jurídica. ${ }^{79}$ A respeito, é importante considerar que a problematização das projeções etnocêntricas da representação ocidental de mundo e sua respectiva concepção de juridicidade, para o qual a análise antropológica naturalmente se vocaciona, não é algo evidente. Conforme enfatiza Le Roy, é necessário se descentrar da experiência ocidental para perceber que a ideia de regra como fundamento da regulação jurídica não é

${ }^{76}$ CARBONNIER, Jean. Flexible droit: pour une sociologie du droit sans rigueur. $10^{\mathrm{a}}$ ed. Paris: Librairie Générale de Droit et de Jurisprudence, 2001.

${ }_{77}$ Cf. LE ROY, Étienne. Le jeu des lois: une anthropologie "dynamique" du Droit: avec des consignes et des conseils au "jeune joueur juriste". Paris: Librairie Générale de Droit et de Jurisprudence, 1999, p. 177 e 202; e LE ROY, Étienne. Le tripode juridique: Variations anthropologiques sur un thème de flexible droit. L'Année sociologique, Vol. 57, 2, 2007, p. 341-351.

${ }^{78}$ Para uma análise mais ampla da crítica de Étienne Le Roy à perspectiva de Jean Carbonnier, ver: VILLAS BÔAS FILHO, Orlando. A regulação jurídica para além de sua forma ocidental de expressão: uma abordagem a partir de Étienne Le Roy. Revista Direito \& Práxis, Vol. 6, 3, 2015, p. 175-178.

${ }_{79}$ Para uma análise dessa questão, ver: VILLAS BÔAS FILHO, Orlando. Juridicidade: uma abordagem crítica à monolatria jurídica enquanto obstáculo epistemológico.

Revista da Faculdade de Direito da USP, Vol. 109, 2014, p. 281-325. 
partilhada por todas as tradições e que, portanto, não é universal nem universalizável. ${ }^{80}$

Partindo da premissa de que a juridicidade é mais ampla que o direito de modo a compreendê-lo, Étienne Le Roy sublinha as quatro propriedades que, em seu entendimento, seriam comuns a ambos ${ }^{81}$ : a) esses dois conjuntos normativos (ensembles normatifs) - melhor seria falar em âmbitos de regulação - correspondem a mundos próprios que exprimem uma visão particular. De um lado, uma visão de mundo institucionalizada com o direito e, de outro, mundos regulados distintamente que, em sua abundância, podem ser multiplicados, escapando, em todo caso, a toda programação; b) direito e juridicidade partilham os mesmos fundamentos, repousando, assim, sobre as mesmas bases normativas que são, conforme visto, as normas gerais e impessoais (NGI), os modelos de conduta e de comportamento (MCC) e os sistemas de disposições duráveis (SDD) articulados, entretanto, a partir de montagens diversas e originais, não somente entre o direito (que prioriza as NGI) e a juridicidade, mas no seio desses dois conjuntos; c) direito e juridicidade organizam de maneira original os quatro tipos ideais de ordenamentos jurídicos (ordonnancements juridiques): ordenamento imposto, aceito, negociado e contestado. Logo, se o direito repousa sobre um modo imposto em virtude de sua concepção de ordem jurídica como instância particular autônoma, a heteronomia da juridicidade e a diversidade de

${ }^{80}$ A respeito, Le Roy ressalta que "il faut être passé au moins par des terrains non éuropéens pour avoir fait l'expérience que l'idée de règle au fondement du droit n'est pas partagée par tous et qu'elle est ni universelle ni facile à universaliser". LE ROY, Étienne. Le tripode juridique: Variations anthropologiques sur un thème de flexible droit. L'Année sociologique, Vol. 57, 2, 2007, p. 345.

${ }^{81}$ Sobre essa questão, ver, por exemplo: LE ROY, Étienne. Place de la juridicité dans la médiation. Jurisprudence: Revue critique, No. 4 (La médiation. Entre renouvellement de l'offre de justice et droit), 2013, p. 204-205; LE ROY, Étienne. La terre de l'autre: Une anthropologie des régimes d'appropriation foncière. Paris: Librairie Générale de Droit et de Jurisprudence-Lextenso, 2011, p. 26; LE ROY, Étienne. Les fondements de la socialisation juridique, entre droit et juridicité. In: Étienne Le Roy (dir.). Pratiques citoyennes de droit (Cahiers d'anthropologie du droit). Paris: Karthala, 2011, p. 175176; LE ROY, Étienne. Autonomie du droit, hétéronomie de la juridicité. In: Rodolfo Sacco (ed.). Le nuove ambizioni del sapere del giurista: antropologia giuridica e traduttologia giuridica. Roma: Accademia Nazionale dei Lincei, 2009, p. 115-116; e LE ROY, Étienne. La révolution de la juridicité, une réponse aux mondialisations. In: II Encontro Nacional de Antropologia do Direito. Paper apresentado. São Paulo, SP: Universidade de São Paulo, 2011, p. 13.

3 JOURNAL OF INSTITUTIONAL STUDIES 2 (2017) 
funções que ela pode preencher levam-na a privilegiar mais os ordenamentos aceito e negociado do que o imposto; d) direito e juridicidade repousam sobre a convenção como modo comum de elaboração da norma/solução. Portanto, se na experiência jurídica ocidental, caracterizada por um direito largamente codificado, a dimensão convencional representa uma forma marginal de regulação que intervém apenas na ausência de uma regra legislativa ou regulamentar, em outros lugares, em que as normas gerais e impessoais (NGI) são raras ou secundárias, o acordo convencional de vontades é a regra, mesmo se sua modificação for forçada ou controlada. ${ }^{82}$

A partir dessas considerações, é possível procurar mapear os traços da juridicidade na mediação, o que serve para indicar que a primeira constituiria o domínio próprio em que a segunda se inscreve. Assim, Étienne Le Roy, procurando mostrar que a experiência da mediação estaria associada à juridicidade, enfoca-a a partir de três dimensões que, em seu entendimento, seriam complementares. ${ }^{83}$ Nesse sentido, em primeiro lugar, focaliza os objetivos dos mediandos ou mediados, ressaltando que, em diversas situações, a resolução do problema que enseja a controvérsia não depende da aplicação de normas gerais $e$ impessoais (NGI) por instâncias formais, demandando, ao contrário, a mobilização de modelos de conduta e de comportamento (MCC) e sistemas de disposições duráveis (SDD), que são muito mais recorrentes no âmbito da juridicidade do que no do direito. Em segundo lugar, assevera que a juridicidade também se expressa na mediação em virtude dos procedimentos nela tipicamente utilizados. ${ }^{84}$ Em terceiro lugar, sublinha

82 Segundo o autor, o "ordenamento imposto" estaria associado ao âmbito das "normas gerais e impessoais" (NGI), o "ordenamento negociado" corresponderia ao domínio dos "modelos de conduta e de comportamento" (MCC) e o "ordenamento aceito" estaria ligado aos "sistemas de disposições duráveis" (SDD). Cf. LE ROY, Étienne. Le jeu des lois: une anthropologie "dynamique" du Droit: avec des consignes et des conseils au "jeune joueur juriste". Paris: Librairie Générale de Droit et de Jurisprudence, 1999, p. 157.

${ }^{83}$ Cf. LE ROY, Étienne. Place de la juridicité dans la médiation. Jurisprudence: Revue critique, No. 4 (La médiation. Entre renouvellement de l'offre de justice et droit), 2013, p. 205.

${ }^{84}$ Nesse particular, o autor alude aos seus trabalhos relativos à negociação na justiça africana e na de menores e esboça o que designa de um "paradigma da argumentação" para a obtenção da paz procurada. Tal paradigma, pretendendo veicular uma taxinomia inspirada na história das instituições gregas, distingue três fases no modus operandi da resolução do conflito: teoria (exposição do problema e dos argumentos), 
que a mediação, na medida em que não se confunde com a atividade jurisdicional, cujo escopo é atribuir a cada um o que lhe é devido, conduz muito mais a uma conciliação ou reconciliação, dialogicamente construída, do que a uma condenação.

\section{CONCLUSÃO}

Este artigo procurou indicar os aportes significativos que a antropologia jurídica pode fornecer à compreensão da mediação. A teoria do multijuridismo de Étienne Le Roy é, nesse sentido, particularmente interessante para esse propósito, pois, ao mobilizar o conceito de juridicidade, permite descentrá-la da dimensão jurídico-formal, essencialmente associada ao plano das normas gerais e impessoais (NGI), de modo a nela incluir também os modelos de conduta de comportamento (MCC) e os sistemas de disposições duráveis (SDD). ${ }^{85}$ Tal como ocorre em relação a diversos outros domínios de análise - das formas de apropriação fundiária às intrincadas dinâmicas regulatórias que caracterizam os regimes de juridicidade atuais, passando pela complexa hibridação de lógicas que caracteriza a transmodernidade ou pela crítica radical à monolatria como obstáculo epistemológico -, a perspectiva desse autor enseja uma tematização inovadora e potencialmente muito frutífera da mediação, uma vez que, inscrevendo-a no horizonte da juridicidade, permite não apenas seu delineamento conceitual em termos mais consequentes, como também a explicitação da complexidade que a caracteriza.

A teoria do multijuridismo de Étienne Le Roy, a partir das devidas adaptações, oferece, ademais, um rico quadro analítico para a

crise (confrontação de diferentes versões) e catarse (apaziguamento da controvérsia). Cf. LE ROY, Étienne. Place de la juridicité dans la médiation. Jurisprudence: Revue critique, No. 4 (La médiation. Entre renouvellement de l'offre de justice et droit), 2013, p. 205.

85 Para uma análise da diferença entre norma, normatividade e juridicidade, ver: RUDE-ANTOINE, Edwige; YOUNÈS, Carole; MILLARD, Éric; YOUNÈS, Carole; RUDE-ANTOINE, Edwige. Norme, normativité, juridicité. In: Edwige Rude-Antoine; Geneviève Chrétien-Vernicos (coords.). Anthropologies et droits: état des savoirs et orientations contemporaines. Paris: Dalloz, 2009, p. 77-106. 
compreensão da regulação jurídica no Brasil ${ }^{86}$ Por esse motivo, é de espantar a parca ressonância que até o momento recebeu em nosso debate acadêmico. Sua vocação interdisciplinar pode contribuir muito para o desenvolvimento dos estudos sociojurídicos no País e também para a elucidação de temáticas específicas, tais como a mediação. Conforme ressaltado, a complexidade assumida por certas questões na contemporaneidade implica abordagens que não se mantenham adstritas às clássicas divisões disciplinares. É nesse sentido que autores como Jacques Commaille, rejeitando clivagens artificiais no âmbito das ciências sociais, defendem resolutamente o desenvolvimento de uma pesquisa interdisciplinar relativamente à regulação jurídica. ${ }^{87}$ Remetendo a Fernand Braudel e Immanuel Wallerstein, com os quais mantém clara relação de afinidade, Jacques Commaille enfatiza que a manutenção de fronteiras entre as ciências sociais hoje decorreria mais de conveniências institucionais ou coorporativas do que propriamente de razões cognitivas. ${ }^{88}$

Em sentido análogo, André-Jean Arnaud também questionava a compartimentalização disciplinar e propunha a construção de um campo

${ }^{86}$ Cf. VILLAS BÔAS FILHO, Orlando. A juridicização e o campo indigenista no Brasil: uma abordagem interdisciplinar. Revista da Faculdade de Direito da USP, Vol. 111, 2016, p. 339-379.

${ }^{87}$ Cf. COMMAILLE, Jacques. À quoi nous sert le droit? Paris: Gallimard, 2015, p. 2425; e COMMAILLE, Jacques. À quoi nous sert le droit pour comprendre sociologiquement les incertitudes des sociétés contemporaines? SociologieS (Dossiers, Sociétés en mouvement), 07 mar. 2016, 2016, p. 12. Disponível em: $<$ http://sociologies.revues.org/5278>. Acesso em: 5 de fevereiro de 2018.

${ }^{88} \mathrm{Cf}$. COMMAILLE, Jacques. De la "sociologie juridique" à une sociologie politique du droit. In: COMMAILLE, Jacques; DUMOULIN, Laurence; ROBERT, Cécile (Dir.). La juridicisation du politique. Paris: Librairie Générale de Droit et de JurisprudenceLextenso, 2010, p. 38; COMMAILLE, Jacques. Nouvelle économie de la légalité, nouvelles formes de justice, nouveau régime de connaissance: L'anthropologie du droit avait-elle raison? In: Christoph Eberhard; Geneviève Vernicos (dir.). La quête anthropologique du droit: Autour de la démarche d'Étienne Le Roy. Paris: Karthala, 2006, p. 351-352 e 368; e COMMAILLE, Jacques; DURAN, Patrice. Pour une sociologie politique du droit: présentation. L'Année Sociologique, Vol. 59, 1, 2009, p. 12-13. A respeito, ver: VILLAS BÔAS FILHO, Orlando. A juridicização e a judiciarização enfocadas a partir da "sociologia política do direito" de Jacques Commaille. Revista Brasileira de Sociologia do Direito, Vol. 2, 2, 2015, p. 58. 
comum para a análise jurídica. ${ }^{89}$ É evidente que, conforme ressaltado na introdução, são necessários os cuidados, sublinhados por autores como Jacques Caillosse, para que a interdisciplinaridade não descambe para um ecumenismo ingênuo. Por outro lado, também não se trata de desconsiderar as dificuldades ínsitas a essa empreitada. ${ }^{90}$ Contudo, ela se torna cada vez mais necessária de modo a confirmar o que já vislumbrara o historiador Fernand Braudel, em 1958, ao propugnar a necessidade de um mercado comum entre as ciências sociais. ${ }^{91}$ Referindo-se à mediação, Étienne Le Roy também pontuava, desde pelo menos meados da década de 1990, a necessidade de uma abordagem interdisciplinar nas ciências sociais, sustentando seu enraizamento na pesquisa de campo, na construção de novos modelos analíticos e na comparação de diferentes interpretações. ${ }^{92}$ Entretanto, a implementação de algo semelhante a isso no Brasil se situa menos em nosso espaço de experiência do que em nosso horizonte de expectativas.

${ }^{89}$ Nesse sentido, é paradigmático o artigo intitulado "Droit et Société: un carrefour interdisciplinaire", publicado em 1988, e posteriormente integrado aos livros Le droit trahi par la sociologie e O direito traído pela filosofia. Cf. ARNAUD, André-Jean. Droit et Société: du constat à la construction d'un champ commun. Droit et Société, No. 20-21, 1992, p. 18; ARNAUD, André-Jean. Le droit trahi par la sociologie: Une pratique de l'histoire. Paris: Librairie Générale de Droit et de Jurisprudence, 1998, p. 77; e ARNAUD, André-Jean. O Direito traído pela filosofia. Trad. Wanda Capeller e Luciano Oliveira. Porto Alegre, RS: Fabris Ed., 1991, p. 220.

${ }^{90} \mathrm{Cf}$. CAPELLER, Wanda. De que lugar falamos? Retomando um velho papo sobre o Direito e a Sociologia. Revista de Estudos Empíricos em Direito, Vol. 2, 1, 2015, p. 12. ${ }^{91}$ Sobre esse ponto, o grande historiador francês já preconizava que "ainsi, malgré les réticences, les oppositions, les ignorances tranquilles, la mise en place d'un 'marché commun' s'esquisse; elle vaudrait la peine d'être tentée au cours des années qui viennent, même si, plus tard, chaque science avait avantage, pour un temps, à reprendre une route plus étroitement personnelle". BRAUDEL, Fernand. Historie et Sciences Sociales: la longue durée. Annales: Économies, Sociétés, Civilisations, Vol. 13, 4, 1958, p. 726.

${ }_{92}$ Cf. LE ROY, Étienne. La médiation mode d'emploi. Droit et Société, No. 29, 1995, p. 54. Sobre a importância da pesquisa de campo na antropologia social, ver, por exemplo: ROULAND, Norbert. Terrains et territoires. In: Caroline Regad (dir.). Aux limites du droit. Paris: Mare \& Martin, 2016, p. 95-103. A respeito, cabe aludir à noção de "autoridade etnográfica" proposta por James Clifford para analisar as estratégias utilizadas pelos antropólogos para legitimar seus relatos. Cf. CLIFFORD, James. On ethnographic authority. Representations, No. 2, 1983, p. 118-146. 


\section{V.REFERÊNCIAS}

ARNAUD, André-Jean. Droit et Société: du constat à la construction d'un champ commun. Droit et Société, No. 20-21, 1992.

. Jean Carbonnier: Un juriste dans la cité. Paris: Librairie Générale de Droit et de Jurisprudence-Lextenso, 2012.

. La gouvernance: Un outil de participation. Paris: Librairie Générale de Droit et de Jurisprudence-Lextenso, 2014.

. Le droit trahi par la sociologie: Une pratique de l'histoire.

Paris: Librairie Générale de Droit et de Jurisprudence, 1998.

. O Direito traído pela filosofia. Trad. Wanda Capeller e Luciano Oliveira. Porto Alegre, RS: Fabris Ed., 1991.

ARNAUD, André-Jean; NOREAU, Pierre. The Sociology of Law in France: Trends and Paradigms. Journal of Law and Society, Vol. 25, 2, 1998.

ASSIER-ANDRIEU, Louis. O Direito nas Sociedades Humanas. Trad. Maria Ermantina Galvão. São Paulo, SP: Martins Fontes, 2000.

BERIAIN, Josetxo. Representaciones colectivas y proyecto de modernidad. Barcelona: Anthropos, 1990.

BONAFÉ-SCHMITT, Jean-Pierre. Les modèles de médiation: modèles latins et anglo-saxons de médiation. Jurisprudence: Revue critique, No. 4 (La médiation. Entre renouvellement de l'offre de justice et droit), 2013. 
BOURDIEU, Pierre. Habitus, code et codification. Actes de la Recherche en Sciences Sociales, Vol. 64, 1, 1986.

. La force du droit: éléments pour une sociologie du champ juridique. Actes de la Recherche en Sciences Sociales, Vol. 64, 1, 1986.

. Les juristes, gardiens de l'hypocrisie collective. In: François Chazel; Jacques Commaille (dir.). Normes juridiques et régulation sociale. Paris: Librairie Générale de Droit et de Jurisprudence, 1991.

2012.

. Sur l'État. Cours au Collège de France 1989-1992. Paris: Seuil,

BOURDIEU, Pierre; CHAMBOREDON, Jean-Claude; PASSERON, JeanClaude. Le métier de sociologue. $5^{\mathrm{a}}$ ed. Berlin: Mouton de Gruyter, 2005.

BOURDIEU, Pierre; CHARTIER, Roger. Le sociologue et l'historien. Paris: Raisons d'Agir, 2010.

BRAUDEL, Fernand. Historie et Sciences Sociales: la longue durée. Annales: Économies, Sociétés, Civilisations, Vol. 13, 4, 1958.

CAILLOSSE, Jacques. La sociologie politique du droit, le droit et les juristes. Droit et Société, No. 77, 2011.

CAPELLER, Wanda. De que lugar falamos? Retomando um velho papo sobre o Direito e a Sociologia. Revista de Estudos Empíricos em Direito, Vol. 2, 1, 2015.

CARBONNIER, Jean. Flexible droit: pour une sociologie du droit sans rigueur. 10a ed. Paris: Librairie Générale de Droit et de Jurisprudence, 2001. 
. Sociologie juridique. $2^{a}$ ed. Paris: Presses Universitaires de France, 2008.

CLIFFORD, James. On ethnographic authority. Representations, No. 2, 1983.

COMMAILLE, Jacques. À quoi nous sert le droit? Paris: Gallimard, 2015.

. À quoi nous sert le droit pour comprendre sociologiquement les incertitudes des sociétés contemporaines? SociologieS (Dossiers, Sociétés en mouvement), 07 mar. 2016, 2016. Disponível em:

$<$ http://sociologies.revues.org/5278>. Acesso em: 5 de fevereiro de 2018.

. De la "sociologie juridique" à une sociologie politique du droit. In: COMMAILLE, Jacques; DUMOULIN, Laurence; ROBERT, Cécile (Dir.). La juridicisation du politique. Paris: Librairie Générale de Droit et de Jurisprudence-Lextenso, 2010.

. Nouvelle économie de la légalité, nouvelles formes de justice, nouveau régime de connaissance: L'anthropologie du droit avait-elle raison? In: Christoph Eberhard; Geneviève Vernicos (dir.). La quête anthropologique du droit: Autour de la démarche d'Étienne Le Roy. Paris: Karthala, 2006.

COMMAILLE, Jacques; DURAN, Patrice. Pour une sociologie politique du droit: présentation. L'Année Sociologique, Vol. 59, 1, 2009.

DELPEUCH, Thierry; DUMOULIN, Laurence; GALEMBERT, Claire de. Sociologie du droit et de la justice. Paris: Armand Colin, 2014.

DUPRET, Baudouin. Réflexions sur le concept de droit à partir de quelques cas limites. Droit et Société, No. 94, 2016. 
EBERHARD, Christoph. Le droit au miroir des cultures: pour une autre mondialisation. Paris: Librairie Générale de Droit et de JurisprudenceLextenso, 2010.

. Penser le pluralisme juridique de manière pluraliste: Défi pour une théorie interculturelle du droit. In: Étienne Le Roy (dir.) Les Pluralismes Juridiques (Cahiers d'Anthropologie du Droit). Paris: Karthala, 2003.

. Towards an Intercultural Legal Theory: the Dialogical Challenge. Social \& Legal Studies, Vol. 10, 2, 2001.

FAGET, Jacques. Éloge du fluide: Une lecture sociopolitique de la médiation. In: Christoph Eberhard; Geneviève Vernicos (dir.). La quête anthropologique du droit: Autour de la démarche d'Étienne Le Roy. Paris: Karthala, 2006.

. Les vies écartelées de la médiation. Jurisprudence: Revue critique, No. 4 (La médiation. Entre renouvellement de l'offre de justice et droit), 2013.

FARIA, José Eduardo. Estado, Sociedade e Direito. In: José Eduardo Faria; Rolf Kuntz. Qual o futuro dos direitos? Estado, mercado e justiça na reestruturação capitalista. São Paulo, SP: Max Limonad, 2002.

. Sociologia Jurídica: Direito e Conjuntura. $2^{\mathrm{a}}$ ed. São Paulo, SP: Saraiva, 2010.

FOESSEL, Michaël; KERVÉGAN, Jean-François; REVAULT D'ALLONNES, Myriam (dir.). Modernité et sécularisation: Hans Blumenberg, Karl Löwith, Carl Schmitt, Leo Strauss. Paris: CNRS Éditions, 2007. 
GARCÍA VILLEGAS, Mauricio. Les pouvoirs du droit: analyse comparée d'études sociopolitiques du droit. Paris: Librairie Générale de Droit et de Jurisprudence-Lextenso, 2015.

. On Pierre Bourdieu's Legal Thought. Droit et Société, No. 5557, 2004.

GARCÍA VILLEGAS, Mauricio; LEJEUNE, Aude. La sociologie du droit en France: de deux sociologies à la création d'un projet pluridisciplinaire. Revue Interdisciplinaire d'Études Juridiques, Vol. 66, 1, 2011.

GAUCHET, Marcel. Un monde désenchanté? Paris: Pocket, 2007.

GUIBENTIF, Pierre. Foucault, Luhmann, Habermas, Bourdieu: Une génération repense le droit. Paris: Librairie Générale de Droit et de Jurisprudence, 2010.

GUILLAUME-HOFNUNG, Michèle. La médiation. $7^{a}$ ed. Paris: Presses Universitaires de France, 2015.

. La médiation à la croisée des chemins, des responsabilités à prendre. Jurisprudence: Revue critique, No. 4 (La médiation. Entre renouvellement de l'offre de justice et droit), 2013.

. Le concept de médiation et l'urgence théorique. Les Cahiers du CREMOC, n. 35, 2002.

HARTOG, François. De l'histoire universelle à l'histoire globale? Expériences du temps. Le Débat: Écrire l'histoire du monde, No. 154, 2009.

. Régimes d'historicité: Présentisme et expériences du temps. Paris: Seuil, 2012. 
HÉNAFF, Marcel. Claude Lévi-Strauss et l'anthropologie structurale. Paris: Belfond, 1991.

KANT DE LIMA, Roberto. Ensaios de Antropologia e de Direito: acesso à justiça e processos institucionais de administração de conflitos e produção da verdade jurídica em uma perspectiva comparada. Rio de Janeiro, RJ: Lumen Juris, 2008.

LE ROY, Étienne. Autonomie du droit, hétéronomie de la juridicité. In: Rodolfo Sacco (ed.). Le nuove ambizioni del sapere del giurista: antropologia giuridica e traduttologia giuridica. Roma: Accademia Nazionale dei Lincei, 2009.

. Des Communs ‘à double révolution'. Droit et Société, No. 94, 2016.

. La conciliation et les modes précontentieux de règlement des conflits. Bulletin de liaison du laboratoire d'anthropologie juridique de Paris, No. 12, 1987.

. La médiation comme 'dialogie' entre les ordonnancements de régulation sociale. In: Carole Younès; Étienne Le Roy (dir.). Médiation et diversité culturelle: Pour quelle société? Paris: Karthala, 2002.

. La médiation mode d'emploi. Droit et Société, No. 29, 1995.

. La révolution de la juridicité, une réponse aux mondialisations. In: II Encontro Nacional de Antropologia do Direito. Paper apresentado. São Paulo, SP: Universidade de São Paulo, 2011.

. La terre de l'autre: Une anthropologie des régimes

d'appropriation foncière. Paris: Librairie Générale de Droit et de Jurisprudence-Lextenso, 2011. 
. La voie étroite de la médiation, entre les ordonnancements imposé et négocié de régulation des différends. Négociations: conflit, décision et délibération, Vol. 28, 2, 2017.

. Le jeu des lois: une anthropologie "dynamique" du Droit: avec des consignes et des conseils au "jeune joueur juriste". Paris: Librairie Générale de Droit et de Jurisprudence, 1999.

. Le pluralisme juridique aujourd'hui ou l'enjeu de la juridicité. In: Étienne Le Roy (dir.) Les Pluralismes Juridiques (Cahiers d'Anthropologie du Droit). Paris: Karthala, 2003.

. Le tripode juridique: Variations anthropologiques sur un thème de flexible droit. L'Année sociologique, Vol. 57, 2, 2007.

. Les africains et l'institution de la justice: Entre mimétismes et métissages. Paris: Dalloz, 2004.

. Les fondements de la socialisation juridique, entre droit et juridicité. In: Étienne Le Roy (dir.). Pratiques citoyennes de droit (Cahiers d'anthropologie du droit). Paris: Karthala, 2011.

. L'hypothèse du multijuridisme dans un contexte de sortie de modernité. In: Andrée Lajoie; Roderick MacDonald; Richard Janda; Guy Rocher (dir.). Théories et émergence du droit: pluralisme, surdétermination et effectivité. Bruxelles: Bruylant, 1998.

. Place de la juridicité dans la médiation. Jurisprudence: Revue critique, No. 4 (La médiation. Entre renouvellement de l'offre de justice et droit), 2013. 
. Pour une anthropologie de la juridicité. In: Étienne Le Roy (dir.). Anthropologie et droit: intersections et confrontations (Cahiers d'anthropologie du droit). Paris: Karthala, 2004.

LENOIR, Remi. Du droit au champ juridique. In: Louis Pinto; Gisèle Sapiro; Patrick Champagne (dir.). Pierre Bourdieu, sociologue. Paris: Fayard, 2004.

LÉVI-STRAUSS, Claude. Anthropologie structurale deux. Paris: Plon, 1996.

MacDONALD, Roderick; SAVOIE, Pierre-Olivier. Une phénoménologie des modes alternatifs de résolution des conflits: résultat, processus et symbolisme. In: Christoph Eberhard; Geneviève Vernicos (dir.). La quête anthropologique du droit: Autour de la démarche d'Étienne Le Roy. Paris: Karthala, 2006.

MATTEI, Ugo; NADER, Laura. Plunder: when the rule of law is illegal. Oxford: Blackwell Publishing, 2008.

MILLARD, Éric; YOUNÈS, Carole; RUDE-ANTOINE, Edwige. Norme, normativité, juridicité. In: Edwige Rude-Antoine; Geneviève ChrétienVernicos (coords.). Anthropologies et droits: état des savoirs et orientations contemporaines. Paris: Dalloz, 2009.

NADER, Laura. The life of the law: anthropological projects. Berkeley, CA: University of California Press, 2002.

NICÁCIO, Camila Silva. Direito e mediação de conflitos: entre metamorfose da regulação social e administração plural da justiça. Revista da Faculdade de Direito da UFMG, No. 59, 2011.

. La médiation: un projet de société? Aux origines du Forum de la société civile sur la médiation (FSCM). In: Étienne Le Roy (dir.). 
Pratiques citoyennes de droit (Cahiers d'anthropologie du droit). Paris: Karthala, 2011.

. Médiation face à la reconfiguration de l'enseignement et de la pratique du droit: défis et impasses à la socialisation juridique.

Jurisprudence: Revue critique, No. 4 (La médiation. Entre renouvellement de l'offre de justice et droit), 2013.

NICOLAU, Gilda. Entre médiation et droit, les enjeux d'une bonne intelligence. Jurisprudence: Revue critique, No. 4 (La médiation. Entre renouvellement de l'offre de justice et droit), 2013.

. Éprouver le droit, instituer la vie: Médiation et cadre judiciaire. In: Christoph Eberhard; Geneviève Vernicos (dir.). La quête anthropologique du droit: Autour de la démarche d'Étienne Le Roy. Paris: Karthala, 2006.

ROULAND, Norbert. Anthropologie juridique. Paris: Presses Universitaires de France, 1988.

. L'anthropologie juridique. $2^{\mathrm{a}}$ ed. Paris: Presses Universitaires de France, 1995.

. Nos confins do Direito: Antropologia Jurídica da

modernidade. Trad. Maria Ermantina de Almeida Prado Galvão. São Paulo, SP: Martins Fontes, 2003.

. Terrains et territoires. In: Caroline Regad (dir.). Aux limites du droit. Paris: Mare \& Martin, 2016.

SCHRITZMEYER, Ana Lúcia Pastore. Anthropologie, droit et médiation au Brésil: un champ dialogique en construction. Jurisprudence: Revue critique, No. 4 (La médiation. Entre renouvellement de l'offre de justice et droit), 2013. 
VANDERLINDEN, Jacques. Les Pluralismes juridiques. In: Edwige Rude-Antoine; Geneviève Chrétien-Vernicos (coords.). Anthropologies et droits: état des savoirs et orientations contemporaines. Paris: Dalloz, 2009.

. Réseaux, pyramide et pluralisme ou regards sur la rencontre de deux aspirants-paradigmes de la science juridique. In: Jacques Vanderlinden. Les pluralismes juridiques. Bruxelles: Bruylant, 2013.

VILLAS BÔAS FILHO, Orlando. A governança em suas múltiplas formas de expressão: o delineamento conceitual de um fenômeno complexo. Revista Estudos Institucionais, Vol. 2, 2, 2016.

. A juridicização e o campo indigenista no Brasil: uma abordagem interdisciplinar. Revista da Faculdade de Direito da USP, Vol. 111, 2016.

. A juridicização e a judiciarização enfocadas a partir da "sociologia política do direito" de Jacques Commaille. Revista Brasileira de Sociologia do Direito, Vol. 2, 2, 2015.

A questão da universalidade das categorias jurídicas ocidentais a partir da abordagem antropológica: nota sobre a discussão entre Max Gluckman e Paul Bohannan. Revista da Faculdade de Direito da USP, Vol. 110, 2015.

A regulação jurídica para além de sua forma ocidental de expressão: uma abordagem a partir de Étienne Le Roy. Revista Direito \& Práxis, Vol. 6, 3, 2015.

As transformações da regulação jurídica na sociedade contemporânea: a governança como paradigma. Revista Direito GV, Vol. 12, 1, 2016. Resenha de: ARNAUD, André-Jean. La gouvernance. 
Un outil de participation. Paris: Librairie Générale de Droit et de Jurisprudence-Lextenso, 2014.

. Juridicidade: uma abordagem crítica à monolatria jurídica enquanto obstáculo epistemológico. Revista da Faculdade de Direito da USP, Vol. 109, 2014.

. O direito de qual sociedade? Os limites da descrição sociológica de Niklas Luhmann acerca do direito a partir da crítica antropológica. In: Alberto Febbrajo; Fernando Rister Sousa Lima; Márcio Pugliesi (Orgs.). Sociologia do Direito: Teoria e Práxis. Curitiba, PR: Juruá, 2015.

- O impacto da governança sobre a regulação jurídica contemporânea: uma abordagem a partir de André-Jean Arnaud. Revista Eletrónica Direito e Sociedade - REDES, Vol. 4, 1, 2016.

VIVEIROS DE CASTRO, Eduardo. A inconstância da alma selvagem e outros ensaios de antropologia. São Paulo, SP: Cosac \& Naify, 2002.

YOUNÈS, Carole; LOTETEKA, Jackie. La place du tiers dans la médiation. In: Christoph Eberhard; Geneviève Vernicos (dir.). La quête anthropologique du droit: Autour de la démarche d'Étienne Le Roy. Paris: Karthala, 2006.

\author{
A Mediação em um Campo de Análise Interdisciplinar: \\ o aporte da Teoria do Multijuridismo de Étienne Le Roy \\ Mediation in a Field of Interdisciplinary Analysis: \\ the contribution of Étienne Le Roy's Theory of Multijurisdism \\ Submetido em: 2017-10-23 \\ Aceito em: 2018-01-29
}

